\title{
EL CINE EN LAS PROVINCIAS ARGENTINAS DESDE LAS REVISTAS PORTEÑAS
}

\author{
Cinema in the Argentine Provinces as seen in Buenos Aires Magazines
}

\author{
María Constanza Grela Reina* \\ https://orcid.org/0000-0002-8343-3543 \\ Lesly Peterlini** \\ https://orcid.org/0000-0002-3298-1929
}

\section{Resumen}

El cine estuvo presente desde tiempos muy tempranos en las provincias de nuestro país, aunque poco se refleja en los estudios de cine argentino que se hacen eco, casi exclusivamente, de las producciones realizadas desde el Área Metropolitana de Buenos Aires. Esto incide directamente en la conformación de una lectura parcial de los procesos cinematográficos de la Argentina. Encontramos necesaria la construcción de un panorama total del cine nacional y para ello las publicaciones periódicas especializadas, abocadas al estudio del cine, significan un gran aporte a la hora de rastrear la realización de producciones regionales, reconstruir los circuitos y formas de distribución/exhibición e indagar en los modos de recepción. Analizaremos las publicaciones periódicas Cinegraf, Cine Universal, La película. Semanario cinematográfico sudamericano, Cine Club Argentino. Boletín mensual Cine Mínimo, Todo lo referente al cine de 16, 9 y 1/2 y 8 milímetros, Radiofilm, y otras de relevancia, publicadas en la Ciudad de Buenos Aires entre 1914 y 1959, a fin de rescatar la mirada sobre el cine regional desde el ámbito porteño. Estas revistas cuentan con corresponsales, corredores y contactos comerciales en las provincias y se observa un caudal de información específica que facilita la ampliación y profundización de la actual historiografía sobre cine argentino.

$<$ Historia del Cine $><$ Cine argentino $><$ Cines Regionales $><$ Revistas de Cine $>$

\begin{abstract}
Since early times cinema was very much alive in the provinces of our country, although it is vaguely included in Argentine film history. Researchers and historians focused almost exclusively on productions made within the Buenos Aires Metropolitan Area. This results in a partial reading of the cinematographic processes in Argentina. We find it necessary to build a complete panorama of national cinema and, in order to do so, specialized periodical publications, devoted to the study of cinema, mean a great contribution when it comes to tracking down the production of regional films, reconstructing the circuits of distribution/ exhibition, and inquiring into forms of spectatorship. We will analyze the periodical publications Cinegraf, Cine Universal, La película. Semanario cinematográfico sudamericano, Radiofilm, Cine Club Argentino, Boletín mensual and other with equals relevance, published in Buenos Aires between 1914 and 1959, in order to find the way journalists, critics, and spectators conceived regional cinema. These magazines have correspondents, colleagues, and comercial contacts in the provinces, thus delivering specific information that helps to extend and deepen the current historiography on Argentine cinema.

$<$ History of Cinema $><$ Argentine Cinema $><$ Regional Cinemas $><$ Cinema Magazines $>$

Recibido: 28/09/2020//Aceptado: 20/11/2020

\footnotetext{
* Instituto de Historia del Arte Argentino y Latinoamericano, Facultad de Filosofía y Letras, Universidad de Buenos Aires (UBA), Argentina, constanzagrela@gmail.com

** Instituto de Historia del Arte Argentino y Latinoamericano, Facultad de Filosofía y Letras, Universidad de Buenos Aires (UBA), Argentina, lesliepeterlini@gmail.com
} 
Grela Reina y Peterlini. El cine en las provincias argentinas desde las revistas porteñas.

\section{Introducción}

El cine estuvo presente desde tiempos muy tempranos en las provincias de nuestro país, aunque poco se refleja en los estudios de cine argentino que se hacen eco, casi exclusivamente, de las producciones realizadas en la Ciudad de Buenos Aires y sus cercanías. Esto incide directamente en la conformación de una lectura parcial de los procesos cinematográficos de la Argentina. Las investigadoras Pardo (2016), Kriger (2014) y Ciancio (2013) han realizado en sus trabajos un repaso por la historia de la historiografía sobre cine en Argentina. En ellos salta a la vista que desde las primeras publicaciones como la Historia ligera de Leopoldo Torres Ríos del año 1922, o los escritos de Horacio Quiroga — que fueron fechados entre 1919 y 1931—, pasando por textos emblemáticos como Historias del cine argentino de Di Núbila (1959), hasta producciones más contemporáneas como Cine argentino. Industria y clasicismo de España (2000), la perspectiva de estudio ha estado mayormente centrada en las producciones realizadas en la ciudad de Buenos Aires. Pocas veces dirigen su mirada a los acontecimientos ocurridos, en torno al cine, en las provincias argentinas. Sin embargo, como se ha comenzado a divulgar y a conocer en los últimos años, el cine estuvo presente en todo nuestro territorio desde tiempos tempranos.

Entendemos que una historia regional del cine, en su observación de los procesos cinematográficos en regiones, provincias, áreas o núcleos (Flores, 2019), engrandece la discusión acerca de la noción de cine nacional, inseparable de sus especificidades locales. Frente a este horizonte, buscamos colaborar en la extensión del conocimiento sobre el cine en las provincias que componen la República Argentina a través de un relevamiento y estudio de las publicaciones periódicas especializadas en cine, disponibles en la hemeroteca de la Biblioteca Nacional ${ }^{1}$. Las revistas especializadas pueden proveernos de información vinculada a los cines regionales, habitualmente dejada de lado en la bibliografía sobre cine argentino. En su introducción al catálogo de revistas Páginas de cine, Clara Kriger acierta al afirmar que "las revistas de cine consiguieron mediatizar rápidamente las expectativas de un público ávido por conectarse con los astros, las innovaciones técnicas, las interpretaciones y teorías relacionadas con el medio y los detalles de todo tipo que pudieran contribuir a completar el universo de sentidos que propone cada película" (Kriger, 2003, p.5). Creemos que este análisis contribuye a reconstruir el universo cinematográfico nacional en torno a la producción, exhibición, distribución y recepción, ampliando nuestros conocimientos sobre el modo en que el cine fue concebido en los variados lugares y contextos del país.

Las revistas localizadas y analizadas en este artículo son editadas en la Ciudad de Buenos Aires. Su mirada y contenido hacen foco en su propio cine, destinando solo un breve espacio, de frecuencia irregular, al espectáculo cinematográfico en las provincias

\footnotetext{
${ }^{1}$ Hacemos referencia a la investigación que desarrollamos en el curso de la Beca Josefa Emilia Sabor II (2018), otorgada por la Biblioteca Nacional de la República Argentina Mariano Moreno. Este concurso promueve la formación de repertorios bibliográficos especializados e índices de publicaciones periódicas a partir del acervo de la institución. La pesquisa se acotó únicamente a las existencias en el mencionado acervo, por lo que es, sin dudas, una lectura parcial o fragmentaria pudiendo existir números de las revistas en otros depósitos o archivos del país.
} 
argentinas. No obstante, había corresponsales, corredores y contactos comerciales en el interior que informaban acerca de lo sucedido en cada región. Es posible encontrar en el contenido de estas revistas pequeñas secciones, notas, crónicas, publicidades e informes destinados a la actividad cinematográfica regional, en los que se observa no sólo la producción de películas sino también la apertura de nuevas salas de cine, los estrenos locales, nacionales e internacionales, las visitas de elencos y directores, los hábitos y preferencias del público, las características de las salas y espacios alternativos de exhibición, sus programas por función, entre más acontecimientos ligados al campo cinematográfico. En la mayoría de estas publicaciones periódicas se aprecia, a su vez, una aparición menor de noticias sobre cine nacional respecto del internacional, y esto se vuelve aún más limitado si nos referimos a la actividad cinematográfica en las provincias argentinas. Esta desventaja podría ser explicada por la existencia de un mercado local expectante de novedades provenientes del extranjero, en especial aquellas de Europa y Estados Unidos. Pero de ningún modo implica ausencia de producciones argentinas. Las publicaciones especializadas sobre cine están claramente orientadas hacia la recepción, direccionadas a un público popular y, por lo tanto, reflejan sus gustos. Los lectores esperaban las novedades sobre los estrenos de películas internacionales y ver a las estrellas de esas latitudes. Por esta razón, creemos que la cinematografía local ocupaba un lugar menor en algunas revistas, aunque ello no significa que no hubiese producción. Por el contrario, ésta ha sido prolífica y diversa.

Partiendo de estas apreciaciones iniciales, nuestro objetivo es abordar el análisis de las noticias y artículos sobre la cinematografía en las provincias argentinas, publicados en revistas especializadas durante el periodo silente y clásico (1914-1959), editadas en Buenos Aires. Tomamos 1914 como fecha de partida, este es el año de aparición de la primera publicación especializada en cine, la revista Excelsior. Por su parte, 1959 como fecha límite, es el año en el que se considera concluye el cine clásico industrial, producto de la crisis de los estudios y la aparición de nuevos modelos estéticos. Las principales fuentes ${ }^{2}$ consultadas son:

Boletín de la Academia de Artes y Ciencias Cinematográficas de la Argentina (1942)

- Cine Club Argentino. Boletín mensual (1941-1943)

- Cine Mínimo. Todo lo referente al cine de 16, 9 y 1⁄2 y 8 milímetros (19481950)

- Cine Técnica. Tratado técnico-práctico de cinematografía (1941)

- Cine Universal (1919-1921)

- Cinegraf(1936)

- Cinema Chat (1920-1921)

- $\quad$ Cosas de cine (1937-1941)

- Imparcial Film (1918-1920)

2 Los años indicados a continuación son los referidos a los períodos consultados para cada revista y estudiados en esta investigación. 
- La Película. Semanario cinematográfico sudamericano (1919-1922)

- Magazine Cinematográfico (1930)

- Maravillas Films (1930)

- Primer Plano (1951)

- Radiofilm (1949-1959)

- $\quad$ Set (1946-1952)

- Sideral (1933)

En un primer momento, nos acercaremos a ciertas prácticas inherentes al período silente, detectadas a través de estas lecturas periodísticas: las películas panorámicas y su interés para productores, exhibidores y público, la expansión hacia el norte y sur del país de casas distribuidoras de películas, y la persistencia en las provincias de modos de exhibición ya dejados de lado en Buenos Aires. Posteriormente, expondremos una serie de temas identificados en las noticias publicadas durante los años del clásico: la actividad de productoras regionales y la realización de películas en las provincias, la organización de Avant-Premières en salas provinciales, la celebración de festivales de cine en localidades alejadas de la ciudad capital y la formación de espectadores y realizadores a través de las publicaciones para aficionados y los cineclubes.

Aún en sus diferencias, este corpus de publicaciones presenta un punto de vista en común: todas las noticias relevadas fueron escritas desde Buenos Aires. La información era provista por los corresponsales, periodistas colegas, contactos comerciales y los propios operadores y realizadores cinematográficos que viajaban. Pero cada artículo era redactado en la ciudad capital. Es nuestro propósito, al estudiar estas problemáticas encontradas, observar la mirada porteña sobre el quehacer cinematográfico provincial. Las publicaciones periódicas constituyen entonces el núcleo de nuestro trabajo y son examinadas como testimonios/registros de su época. Creemos que el estudio, análisis y puesta en valor que llevamos a cabo colabora en la construcción de un panorama ampliado del cine nacional. Al mismo tiempo, profundiza en el conocimiento sobre la historia del cine argentino, contemplando la producción, las formas de exhibición de películas, los contextos de distribución y la recepción. Así también, pretende explicar la relación existente entre el cine y la comunidad, a fin de reconstruir la práctica cinematográfica en tan diversos contextos culturales y destacar aquellos sucesos ignorados por las historias del cine convencionales.

\section{El cine silente en las revistas especializadas}

El desarrollo del cine silente en Argentina acompaña un proceso de crecimiento y modernización producido en Buenos Aires en los albores del siglo XX. Durante sus primeros años de existencia, las flamantes noticias sobre el cinematógrafo son publicadas en los grandes diarios y su lectura nos transmite el asombro y la fascinación ante el invento. A medida que el país se afianza como mercado potencial para el cine extranjero, las primeras publicaciones especializadas comienzan a dar cuenta del nuevo fenómeno 
y se orientan tanto a quiénes integran el medio como al público en general (Kriger, 2003). Es así que en 1914, año de aparición de la revista Excelsior, especializada en cine y principalmente dirigida a propietarios de salas, se da comienzo al surgimiento de una serie de publicaciones específicamente cinematográficas como las gremiales Imparcial Film y La Película. Semanario Cinematográfico Sudamericano, con información de interés para distribuidores y exhibidores, y las dirigidas al gran público Cinema Chat, Cine Universal y Cinegraf, entre otras.

El cine foráneo es el foco de atención en las revistas de cine argentinas durante el período silente. Imágenes de las estrellas, anuncios de estrenos, reseñas argumentales, cine-novela por entregas, foto-dramas, entrevistas, cartas de lectores, romances y novedades afines a la vida de sus protagonistas, son diferentes formatos de noticias que refieren considerablemente a un mundo cinematográfico extranjero, el común de las veces europeo o hollywoodense. En su estudio pormenorizado sobre la revista Cinegraf, Morales (2017) resalta una contradicción en su línea editorial, la cual piensa también como estructural al campo cinematográfico argentino de los años treinta: a la vez que se incita a la construcción de un cine nacional, éste elabora su material a partir de la cultura hegemónica extranjera. Cinegraf hace su aparición un año antes del nacimiento del cine sonoro, pero esta tendencia es observable desde sus primeros números. Hacia fines del primer decenio comienza a editarse Cinema Chat, casi exclusivamente dedicada a los rumores sobre estrellas extranjeras, y también Cine Universal, la cual reflexiona en sus notas sobre el nuevo invento y su estatuto artístico, toda vez que se orienta a una apreciación del cine como herramienta educativa y de ilustración popular (Kriger, 2003). Se agrega Maravillas Films, que publica su primer ejemplar en 1930, centrada en el ambiente hollywoodense.

Aún así, es posible rastrear sucesos de cine nacional. ${ }^{3}$ Cinegraf se ve poblada de notas sobre la industria cinematográfica extranjera, a la vez que se observan editoriales que refieren en especial a la industria local. ${ }^{4}$ Los artículos en estas revistas suelen hablar del cine vernáculo sin casi nombrar provincias o regiones - a excepción de lugares de explotación turística-, o bien su finalidad es anunciar nuevas asociaciones que van conformándose, con la intención de regular las actividades cinematográficas de alcance nacional. El caso de Imparcial Film es el de una revista dirigida al gremio cinematográfico, que desde 1918 publicaba noticias de utilidad para exhibidores, siendo ágil encontrar en sus páginas información y difusión sobre la distribución y exhibición de películas extranjeras en la Argentina. A la vez, la mayoría de sus notas presentaban un carácter didáctico similar a las de Cine Universal, y así los lectores por fuera del medio profesional también gustaban de leer las últimas noticias sobre sus Stars estadounidenses preferidas.

3 Tal fue la tarea que emprendió Mafud (2016) en el volumen La imagen ausente en el que confecciona un catálogo de películas argentinas de ficción, a partir de revistas cinematográficas entre otras fuentes, para el período 1914-1923.

4 Un ejemplo es la nota referida a la importancia de regular la actividad cinematográfica nacional, velando por la educación general y también por la propaganda argentina en el exterior a través de sus producciones cinematográficas (Cinegraf, $\mathrm{N}^{\circ}$ 53, septiembre 1936). 
En nuestra búsqueda de noticias sobre la actividad cinematográfica regional en la etapa silente, la publicación La Película. Semanario Cinematográfico Sudamericano, ${ }^{5}$ destinada principalmente a compañías distribuidoras y casas exhibidoras, es una fuente más prolífica. Desde sus comienzos, las empresas que alquilaban el material cinematográfico a las distintas compañías exhibidoras anunciaban sus productos en este espacio (Kriger, 2003). En sus notas se expone todo lo relacionado con la apertura de nuevas salas, equipamientos técnicos de reciente fabricación, estrenos nacionales y extranjeros, negocios entre distribuidores y exhibidores, entre otras. Algunas pocas de estas noticias refieren a ciudades del interior y, en ocasiones, una pequeña sección se crea - aunque con intermitencias - sobre la cinematografia argentina exclusivamente y, como sucede a partir de 1921, se añade otro apartado para informar sobre el acontecer del cine en Rosario. ${ }^{6}$ Las notas son, la mayoría de las veces, de una muy breve extensión y rara vez llevan la firma de autor, como sucede habitualmente en el periodismo que coincide con el período silente (Cuarterolo, 2009). Estos simples artículos facilitan rastrear instancias de desarrollo, transición y expansión en torno al cinematógrafo en las provincias: prácticas de exhibición que se discontinúan en Buenos Aires pero permanecen vivas en zonas del interior, intercambios fraudulentos entre distribuidores y salas exhibidoras provinciales, aperturas de nuevas salas de cine en varias regiones, seguimiento de rutas de distribución de las películas atravesando distintas zonas. Mientras que la historia del cine argentino tradicionalmente se concentró en Buenos Aires, estos escuetos artículos, aún en su inicial desarrollo y con su falta de precisión, nos hacen posible aprender cómo se vivieron distintos avatares en torno al cine nacional, en otras regiones del país. En este camino, comentaremos con ejemplos de noticias relevadas en su articulación con los ejes de producción, distribución, exhibición y recepción.

Figura 1. Tapas de las revistas La Película y Cine Universal
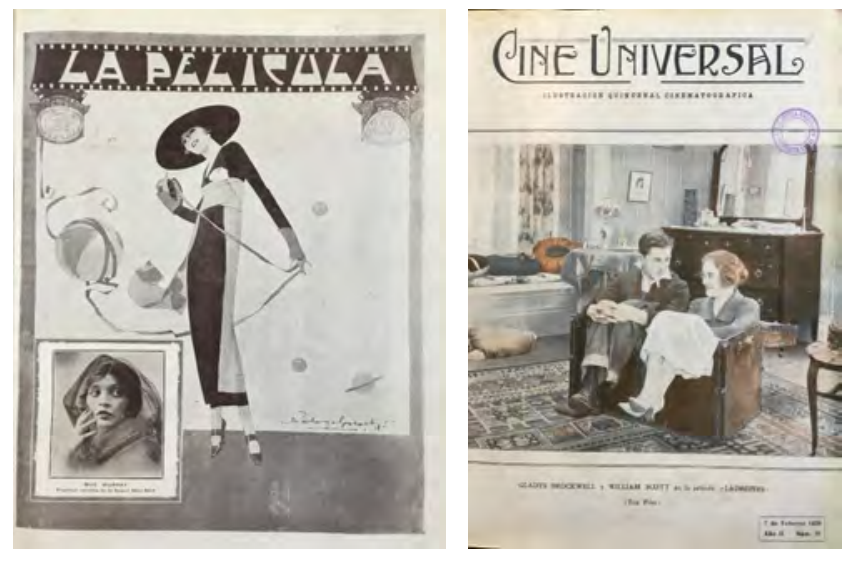

\footnotetext{
En adelante La Película.

6 En la sección "Crónica Rosarina" se anuncian películas de estreno reciente en esta ciudad de la Provincia de Santa Fe, con una corta mención a su éxito de público y crítica (La Película, $\mathrm{N}^{\circ}$ 240, abril 1921). Posteriormente, suelen aparecer bajo el rótulo "De Rosario" u otros afines.
} 


\section{Las panorámicas: patria, conocimiento y beneficios monetarios}

Los paisajes argentinos, los temas criollos y la relación campo-ciudad suelen predominar en las notas del período sobre las producciones argentinas filmadas en el interior. Los redactores gustaban mencionar los viajes de directores porteños hacia las provincias y adelantar el rodaje en curso, entusiasmados por las bellezas paisajísticas. Retomando el análisis de Morales (2017) sobre Cinegraf, la idea del paisaje cinematográfico visto como futuro de un cine nacional es constante en esta revista, que veía también en estas producciones un fin de propaganda argentina en el exterior. En sintonía se encuentra Cine Universal que también celebra las producciones que exhiben el paisajismo nacional, a la vez que dedica notas y entrevistas a las estrellas nacionales (Kriger, 2003). En ocasión del estreno de la película Las Cataratas del Iguazú (1919), filmada por los hermanos Vicente y Luis Scaglione de la casa productora Colón Film, la revista venera su éxito y lamenta que no se distribuyan copias en el extranjero, donde existe interés en los paisajes argentinos, a la vez que se pierde la posibilidad de exhibir la meritoria calidad técnica del film ${ }^{7}$. La idea de nación basada en el territorio se extiende en los films argentinos del período y se corresponde a un país marcado por una inmigración masiva y una cultura heterogénea (Levinson, 2011). Estas películas de viaje abordan la descripción del paisaje sin incluir una acción dramática. Es frecuente encontrar que la iniciativa para filmar películas panorámicas — también llamadas películas naturales o paisajísticas - surge de gobiernos provinciales que suelen encomendar la tarea a directores que trabajan en Buenos Aires.

Así encontramos a José J. Glizó, director de escena cinematográfica y al operador Luis Scaglione, integrantes de Colón Film, regresando de un viaje a Córdoba donde tomaron vistas de paisajes por cuenta del gobierno local. En conjunto estas vistas conforman una película de unos mil quinientos metros donde se aprecia una excelente nitidez fotográfica. La redacción porteña celebra esta iniciativa: "Según parece, el gobierno cordobés piensa hacer conocer en toda la República las bellezas de su territorio provincial, a los efectos de llevar a cabo una intensa propaganda entre los habitantes de Argentina que lo desconocen, a fin de despertar en ellos deseos de visitarla o establecerse en la misma, realizando así una obra inteligente de acción gubernamental". Una aventura de los talleres Federico Valle titulada Hacia el fin del mundo (1921) ${ }^{9}$ es alabada con motivo de su exhibición en los principales cines de Buenos Aires. Se trata de una crónica no ficcional de un viaje de la Corbeta Uruguay, que conduce una comisión de observadores meteorológicos a las islas Orcadas del Sur. Según Cine Universal este film permite comprender los progresos de la técnica cinematográfica alcanzados por los estudios nacionales y despierta una creciente curiosidad en el público. Se valora su fotografía cuidada y el interés pintoresco ${ }^{10}$.

7 Cine Universal, $\mathrm{N}^{\circ}$ 26, diciembre 1919.

8 Cine Universal, $\mathrm{N}^{\circ} 34$, abril 1920, s/p.

9 La película se ha perdido. Andrés Levinson (2011) estudia este film junto a otras películas de viaje rodadas en el sur argentino en el libro Cine en el país del viento. Antártida y Patagonia en el cine argentino de los primeros tiempos.

${ }^{10}$ Cine Universal, $\mathrm{N}^{\circ}$ 62, abril 1921. 
Pese a que La Película no va mucho más lejos en esta mirada, al tratarse de una publicación de interés para distribuidores y propietarios de salas, proporciona más detalle sobre diferencias de posturas y entretelones entre profesionales de la industria. En ocasión del centenario brasileño, la Provincia de Buenos Aires realiza una licitación de cinematografistas para editar una película. La intención es incluir vistas urbanas y campestres, fauna y flora, atractivas estancias, tanto como la exposición de bellos paisajes argentinos de la región bonaerense. Se presentaron distintas casas filmadoras, con sus presupuestos calculados de monto y ganancia prudencial, porque la licitación se otorgaría al que ofreciera su costo más bajo. Federico Valle propone confeccionar el film gratuitamente y el gobierno de la Provincia le adjudica la obra. En opinión de la revista, Valle será visto como un patriota. Sin embargo, serán beneficiarios económicos de este emprendimiento los estancieros, los establecimientos industriales y todos aquellos que paguen los anuncios que aparezcan en la cinta, resultando la película más una exposición de avisos que un film naciona ${ }^{11}$.

En un artículo publicado un año antes, de mayor extensión, los redactores manifiestan la necesidad de fomentar las películas panorámicas argentinas, con insistencia en el público conformado que éstas tienen en Europa y Estados Unidos, dando luz a las razones de su menor producción local. Las películas panorámicas demuestran los progresos de las industrias, las artes y las ciencias de un país, como también sus bellezas naturales. Existe un público que no acepta el cine en su tono cómico o dramatizado y, en cambio, concurre a él para admirar lo paisajístico y lo científico. Los empresarios argentinos no parecen detectar esta curiosidad y rechazan innovar en la realización de panorámicas, con temor a perder público. Es a partir del éxito de la mencionada panorámica argentina Hacia el fin del mundo (1921), con su exposición de los paisajes del sur argentino, que los empresarios parecen cambiar de parecer. Es interesante notar que el semanario, atento al interés de los distribuidores y exhibidores, resalta los aspectos beneficiosos de la panorámica, a saber, el patriótico, el educativo y el monetario:

"No todos conocen las bellezas que nuestro país encierra. La mayoría ignora el tesoro panorámico y esa divulgación hará que cada uno se arraigue el orgullo de ser argentino. Difundir lo desconocido es hacer obra útil y cuando se percate de ello ese público refractario, será el primero en contribuir a su difusión”"12.

\footnotetext{
${ }^{11}$ La Película, $\mathrm{N}^{\circ} 310$, agosto 1922.

${ }^{12}$ La Película, $\mathrm{N}^{\circ}$ 240, abril 1921, p. 7.
} 
Figura 2. Pequeños espacios en primera plana se dedican a la cinematografía nacional

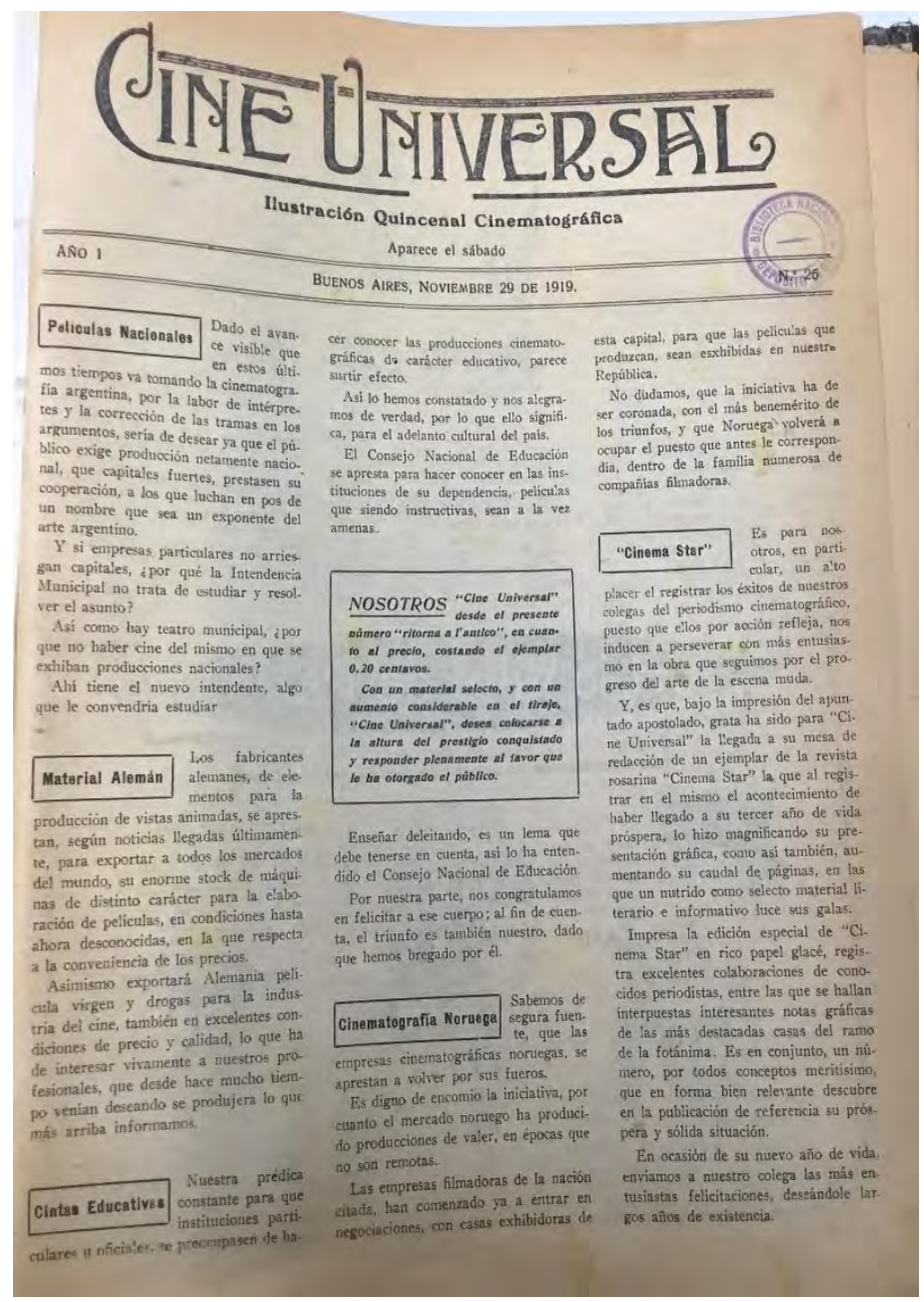

Fuente: Cine Universal, Año I, N 25, noviembre 1919.

\section{Rutas nacionales en la distribución de films}

Los viajes de profesionales de la industria hacia el interior también eran frecuentes para estudiar las posibilidades de distribución de los films en las regiones e instalar sucursales de casas alquiladoras ya existentes en Buenos Aires. Estas empresas alquilaban sus películas a las salas exhibidoras. El circuito de distribución de películas en el período silente es múltiple y cambiante: algunas alquiladoras trabajan en exclusividad con ciertas salas, varias tienen agentes en las regiones que comercializan las películas en distintos cines y otras, incluso, abrían sus propios cines en las provincias. La casa alquiladora Cinematográfica Sud-Americana hace su aparición en 1915 en Buenos 
Grela Reina y Peterlini. El cine en las provincias argentinas desde las revistas porteñas.

Aires, fruto de la integración de dos empresas preexistentes. ${ }^{13}$ Inaugura en 1919 oficinas en las ciudades de Rosario y Bahía Blanca. A partir de la apertura de la sede rosarina, la empresa inicia una gira que continúa hacia el norte, a fin de proyectar nuevas sucursales en Tucumán, Córdoba y Mendoza, entre más provincias. A su vez, desde la sucursal en Bahía Blanca se inicia otro estudio de comercio cinematográfico regional, en este caso en el sur de la Provincia de Buenos Aires. Según La Película "era evidente la necesidad de atender el interior de la República, y así la empresa que nos ocupa ha resuelto instalar oficinas en Rosario y Bahía Blanca, para poder de ese modo satisfacer los crecientes pedidos que se le hacen en ese sentido"14. En este mismo artículo se anuncia la continuidad de la expansión:

"en Rosario se instalaron ya las oficinas de la sucursal, que atenderá la zona norte, donde el espectáculo cinematográfico alcanza ya notable desarrollo (...) Hecho esto en el Norte, la Sud-Americana tiende igualmente a intensificar su acción en el Sud de la provincia y así acaba de partir para Bahía Blanca $(\ldots){ }^{\prime \prime}$.

Es posible identificar dos rutas que parten desde Buenos Aires: una, a través de la ciudad de Rosario, activo polo cinematográfico por estos años y un puente hacia el norte del país, que incluía la región cuyana. ${ }^{16}$ La segunda ruta comprende el tramo hacia Bahía Blanca, que luego enlazaba a otros puntos del sur de la Provincia de Buenos Aires y del país. Esta expansión es efectuada por más empresas alquiladoras y resulta una tendencia. Es el caso de Splendid Program, empresa constituida en Buenos Aires en 1919, que resuelve instalar una sucursal en Rosario para atender las operaciones del norte argentino, con interés en el incipiente desarrollo de esta región ${ }^{17}$. Son sus fundadores y propietarios Manuel M. González, vinculado a la cinematografía hacía tiempo, y Antonio C. Devoto, persona de figuración en el comercio agrícola-ganadero. Splendid Program se propone dar a conocer grandes producciones estadounidenses en el mercado local. Además de administrar la sala Splendid Theatre de Buenos Aires, esta compañía también obtiene la explotación del cine Splendid Theatre en Mar del Plata. Se unen a estas rutas de distribución de películas la Sociedad General Cinematográfica, que funda sucursales en Rosario, Santa Fe, Córdoba, Bahía Blanca, Mendoza, Concordia y Tucumán, y la empresa Sáenz y Mai que instala sucursales en Bahía Blanca y Rosario,

\footnotetext{
${ }^{13}$ La unión de las empresas Cinematográfica Argentina y Compañía Ítalo-Chilena darán lugar a la Cinematográfica Sud Americana. A su vez, la Cinematográfica Argentina fue fundada en 1913 como casa alquiladora de cintas mientras que la Compañía İtalo-Argentina trabajó varios años en el alquiler de películas en Chile y también se dedicaba a la explotación de salas cinematográficas en aquel país ( $L a$ Película, $\mathrm{N}^{\circ} 157$, septiembre 1919).

${ }^{14}$ La Película, $\mathrm{N}^{\circ} 148$, abril 1919, p. 15.

${ }^{15}$ La Película, $\mathrm{N}^{\circ}$ 148, abril 1919, p. 15.

${ }^{16}$ Cuarterolo y Jelicié (en este número) reconstruyen el circuito comercial regional del cine en el artículo Hacia la conquista del norte: el proyecto pionero de la revista Film Gráfico (Tucumán, 1917).

${ }^{17}$ La Película, № 155, septiembre 1919.
} 
entre más ciudades del interior y exterior del país ${ }^{18}$. Posteriormente, esta empresa inauguró otra agencia en Tucumán ${ }^{19}$.

La Sociedad General Cinematográfica es fundada en 1912. En ella se integraron diversas empresas que venían trabajando anteriormente con éxito. Hacia 1919 era la empresa que más cinematógrafos servía, a la vez que poseía dos biógrafos en Buenos Aires. El público argentino debía a esta empresa la introducción de las películas de la Paramount, entre otras producciones de firmas extranjeras ${ }^{20}$. Por su parte, Sáenz y Mai -empresa formada por Manuel Sáenz y Ernesto J. Mai- inicia sus operaciones en 1918, las que incluían la apertura de una sucursal en Montevideo y la explotación de salas cinematográficas de su propiedad en Buenos Aires.

Figura 3. Una pequeña sección denominada "De Rosario" anuncia noticias sobre la cinematografía rosarina

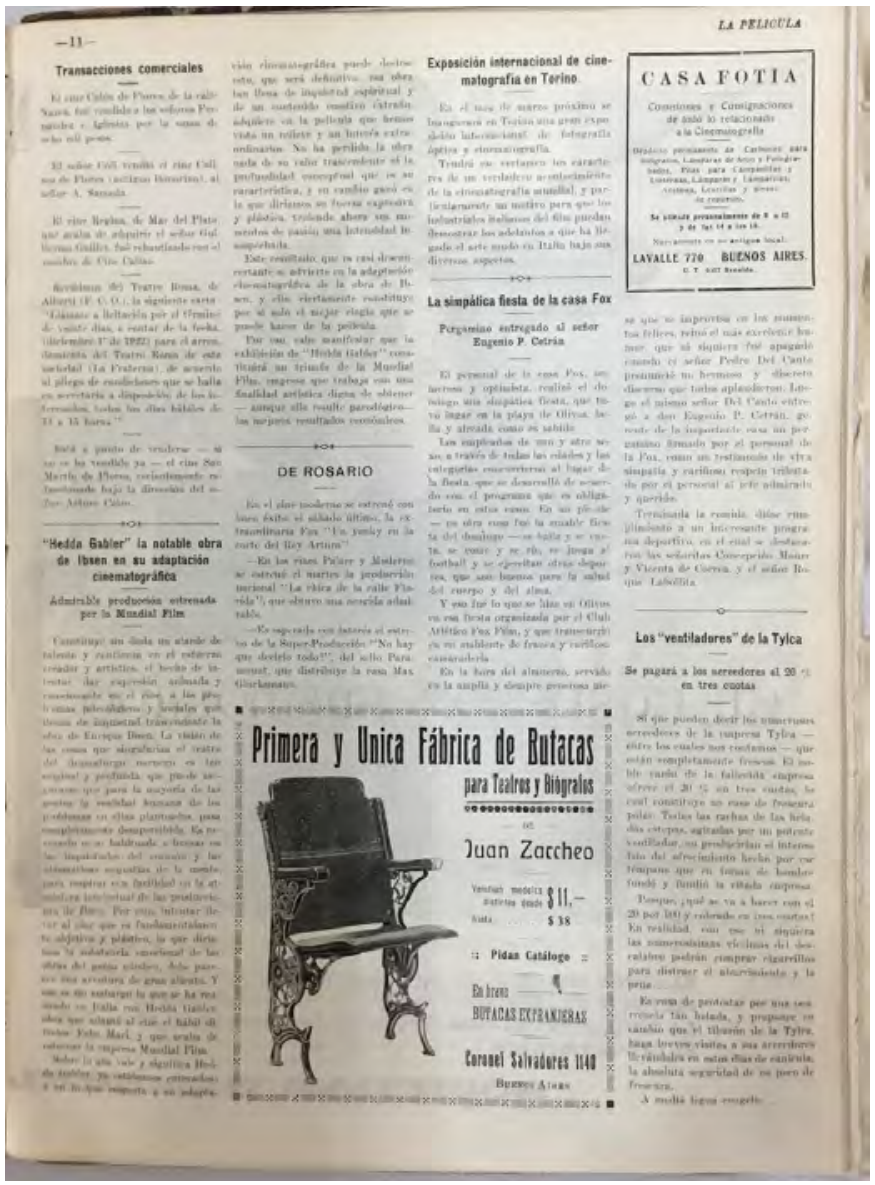

Fuente: La Película, № 324, diciembre 1922.

\footnotetext{
${ }^{18}$ La Película, $\mathrm{N}^{\circ} 157$, septiembre 1919.

${ }^{19}$ La Película, $\mathrm{N}^{\circ} 187$, abril 1920.

${ }^{20}$ La Película, $\mathrm{N}^{\circ} 157$, septiembre 1919.
} 
Estos altos en el camino permitían entonces a los distribuidores ampliar el alcance de los negocios cinematográficos, incluyendo la adquisición de derechos exclusivos de explotación de películas —nacionales y extranjeras- y aún algunas salas de cine. Otro ejemplo es la empresa Demaitre y Cía., de Rosario, que ya poseía la exclusividad de la producción Vitagraph para el norte del país y adquiere las cintas de la Argentine Program para explotarlas en Santa Fe y provincias limítrofes ${ }^{21}$. Estas operaciones comerciales eran habituales en una industria cinematográfica en expansión y delimitaban el recorrido de una película desde su estreno - casi siempre en Buenos Aires pero no exclusivamente- hasta llegar a sus potenciales públicos del interior. Rosario es vista por las casas alquiladoras como la plaza "más importante del interior por converger en ella todo el movimiento cinematográfico del norte"22. No siempre los vínculos entre casas alquiladoras y salas de cine eran prósperos y amables. La iniciativa de proyectar películas gratis en salas de Rosario, modalidad auspiciada principalmente por los cines Social y Moderno, desató enfado incluso entre las alquiladoras de Buenos Aires, que llegan a intervenir al considerar que la entrada gratuita era una amenaza para el negocio del film e injusta hacia sus trabajadores. En una nota, publicada a fines de 1919, les advierte que retirará sus películas de circulación en Rosario de continuar con esta modalidad. La propia redacción de la revista apoya la defensa de las casas alquiladoras, a la vez que manifiesta indignación por el hecho, considerándolo irrisorio y bufonesco ${ }^{23}$.

Otro conflicto tuvo lugar en la Provincia de Buenos Aires entre empresarios de cines del itinerario comprendido entre Olivos, San Fernando, San Isidro y Martínez, por un lado, y por otro, salas de Pergamino, Rojas, Salto Argentino. Se agregan también las casas exhibidoras de Baradero, San Pedro, Zárate y Campana. Estos tres núcleos, unidos entre sí en su distribución de manera similar al recorrido en sus respectivas líneas de tren, se vieron afectados por una práctica común: el propietario de un cine mantiene un contrato con una casa alquiladora para pasar una película. Luego, le pasaría esta misma cinta a los demás cines de zonas cercanas, cuando éstos no han participado de ese contrato. Se trataría, entonces, de una práctica clandestina donde se ven desfavorecidas las casas alquiladoras. La Película se involucra en defenderlas: "Si siguen los exhibidores deshonestos burlando tan descaradamente los intereses de las alquiladoras, publicaremos títulos de los cines, nombres y apellidos de los empresarios"24. La revista citada también expone los infortunios de los cines y defiende sus derechos al observar conductas de comercio desleal, velando así por un funcionamiento más justo en el negocio cinematográfico. Señala la poco confiable conducta de los intermediarios en el interior que se aprovechan, en especial desde Rosario y Buenos Aires, de la inexperiencia de los exhibidores provincianos, vendiéndoles copias gastadas, entre otros perjuicios comerciales. La redacción es firme en pronunciarse a favor de la erradicación de estos falsos intermediarios y en el daño que hacen al comercio cinematográfico: "El gremio no puede tolerar esas incursiones de los reptiles. El negocio ha de ser claro, limpio, y

${ }^{21}$ La Película, № 190, mayo 1920.

${ }^{22}$ La Película, $\mathrm{N}^{\circ} 230$, febrero 1921, p. 7.

${ }^{23}$ La Película, $\mathrm{N}^{\circ} 169$, diciembre 1919.

${ }^{24}$ La Película, $\mathrm{N}^{\circ}$ 309, agosto 1922, p. 9. 
no esas turbias corrientes de los intermediarios, yerba mala, que llega hasta el exhibidor inexperto del interior envolviéndolo con sus promesas de baratura y cinta nueva"25.

En una nota afín, el semanario señala el abandono hacia el interior del país, por parte de las empresas cinematográficas que focalizan en las ciudades, dejando de lado los pueblos pequeños, los más lejanos y los rurales: "El interior se ha descuidado siempre, las empresas se han dedicado al foco de las ciudades dejando a otros que explotasen, a su antojo, al biografista de tierra adentro" ${ }^{26}$. Se mencionan casos de piratería por parte de alquiladores en la Provincia de Buenos Aires y en Rosario: un ejemplo sería la compra de películas a bajo precio para después venderlas a sumas elevadas. Si bien se ha avanzado en regular esta actividad, incluso por fuera de las ciudades, faltaría tratarlo un poco más. Se sugiere explícitamente que el sistema directo es más justo y viable. El intermediario suele querer ganar más de lo debido ${ }^{27}$. Un artículo de mayor detalle trata de la necesidad de emplear los recursos insospechados de las provincias en materia cinematográfica, resaltando la avidez de su público, especialmente en ciudades del norte como Tucumán y otras como Santa Fe, Rosario, Mendoza y Córdoba. La redacción de la revista, con frecuencia en estos años, ofrece de manera explícita su punto de vista sobre estos aconteceres y se interesa activamente en la extensión del negocio cinematográfico en las provincias. Reconoce que las casas alquiladoras han tomado decisiones progresistas al abrir sucursales en el interior, pero señala que aún no es suficiente su labor para descentralizar la actividad cinematográfica, mientras que observa con atención el avance del cine en el norte ${ }^{28}$.

\section{Hacia una exhibición cinematográfica moderna}

Los artículos analizados sobre el transcurrir del cine en las provincias, al estar escritos desde Buenos Aires, facilitan observar instancias de transición entre experiencias que iban dejándose de lado en la gran ciudad pero seguían siendo de interés en el interior. El biógrafo-café, también llamado café-biógrafo, biógrafo con café, cines con café o cine-café, era una práctica de exhibición extendida en Rosario en 1919. La Bolsa, San Martín, Belgrano, Sol de Mayo, La Estrella, Alvear y El Plata eran algunos de los café-biógrafos donde aún se cobraba el precio de entrada a través de la consumición. En sucesivos artículos los redactores de La Película se muestran preocupados por la persistencia de estos biógrafos-cafés. A sus ojos se trata de una práctica deficiente de proyección de películas. Se incita entonces a que se transite, como ya sucede en las grandes capitales, hacia una exhibición de cintas por secciones, donde los espectadores pueden asistir en silencio y ubicados en plateas, manteniendo separados a los cafés en locales adyacentes para concurrir durante los intervalos ${ }^{29}$.

\footnotetext{
${ }^{25}$ La Película, $\mathrm{N}^{\circ} 216$, noviembre 1920, p. 5.

${ }^{26}$ La Película, $\mathrm{N}^{\circ} 215$, noviembre 1920, p. 5.

${ }^{27}$ La Película, $\mathrm{N}^{\circ} 215$, noviembre 1920.

${ }^{28}$ La Película, $\mathrm{N}^{\circ} 159$, octubre 1919.

${ }^{29}$ La Película, № 140, mayo 1919.
} 
En Tucumán, los cinematógrafos también funcionan a través de los biógrafoscafés. Aquí los editores proponen a la ciudad de Tucumán progresar hacia salas de cine que provean todos los adelantos de la época y desdeñan, a su vez, de los cafés-biógrafos considerándolos dispersantes de atención y ruidosos para una exhibición cinematográfica moderna: "El cine es una escuela de arte, de civilización, de ideas progresivas, de elegancia y de exquisitez en la vida. Requieren las exhibiciones meditación, silencio, buenas formas sociales, cierta religiosidad mística propia del culto a lo bueno, a lo bello, a lo artístico.” ${ }^{30}$ Según la investigadora mexicana Rosas Mantecón (2017), la práctica del silencio es un fenómeno complejo y determinado por múltiples factores. Según la autora, el silencio en las salas de cine fue primero asumido por los intelectuales y pudo gradualmente formar parte de un nuevo pacto de recepción cinematográfica -un espectador sentado en silencio y en la oscuridad - a partir de la mejoría arquitectónica de las salas, de la profesionalización del campo cultural, del proceso de formación de públicos y de instancias más amplias de coerción y auto-coerción en las que una contemplación sigilosa y ordenada es vinculada a la civilización. De manera similar, hacer silencio durante la proyección de una película ya era visto por el periodismo porteño de la época como la conducta propicia ante el culto arte cinematográfico, es una práctica más civilizada y afianza la concentración del espectador en la obra. En el nuevo hábito la exhibición no se alterna con charlas, sonidos de tazas y mozos corriendo de mesa en mesa. Lejos de sólo presumir, los editores desde Buenos Aires buscan fomentar, a través de sus escritos, la extensión de esta práctica exhibitoria al territorio provincial.

La revista se inquieta por la continuidad de estos cafés-biógrafos, también populares en Mendoza y Córdoba, donde se presentan películas gastadas por el uso en Buenos Aires y tan sólo unos pocos estrenos recientes ${ }^{31}$. En otro artículo, se señala desventajosa la persistencia de biógrafos con café, en casi todos los pueblos del país, como lugar de exhibición de películas. Para la revista, este modo de ver cine es primitivo, resulta perjudicial para el público e implicaría una competencia desleal y ruinosa para cualquier cinematografista. En los biógrafos con café se exhiben cintas deterioradas. Cada vez que se abre una sala de cine en el interior, los dueños de los cafés la desacreditan ${ }^{32}$. En ocasiones, los lectores de la revista exponían sus puntos de vista y defendían sus intereses. Tal es el caso de un director de la sucursal rosarina de importante empresa alquiladora, que responde a las notas publicadas respecto a los cines con café en el interior. El rosarino defiende esta práctica de exhibición de películas, al sostener que resulta imposible implementar en las provincias las técnicas comerciales de uso habitual en Buenos Aires. Aun así, desde la revista se insiste en afirmar que esta forma de exhibición es problemática, porque se proyectan películas en lastimoso estado y acompañadas de un mal café. Asimismo, no estaría de acuerdo con la negación a nuevas formas de exhibición cuando el interior, con pocos teatros y escasos entretenimientos, se muestra como un público ávido de cine ${ }^{33}$.

\footnotetext{
${ }^{30}$ La Película, $\mathrm{N}^{\circ}$ 141, junio 1919, p. 11.

${ }^{31}$ La Película, $\mathrm{N}^{\circ} 159$, octubre 1919.

${ }^{32}$ La Película, $\mathrm{N}^{\circ} 149$, julio 1919.

${ }^{33}$ La Película, № 165, noviembre 1919.
} 
Figura 4. Nota sobre los biógrafos-cafés en Tucumán

\section{De nuesłpo coppesponsal de Tueumán}

Las noticias que nos eomuniea nuestro corresponsal de Tueumán son sugerentes, sobre el modo de funcionar allí los einematógrafos. Son biógrafos-cafés al estilo de los cines de los villorrios insignificantes, de pequeñas aldeas.

Tucumán es una ciudad importante, digna de entrar en el concierto de las eapitales cultas $y$ de adoptar las eostumbres ilustradas de las modernas metrópolis.

El cine es una eseuela de arte, de eivilización, de ideas pregresivas, de elegancia y de exquisitez en la vida. Requieren las exhibiciones meditación, silencio, buenas formas soci: les, cierta religiosidad mística propia del culto a lo bueno, a lo bello, a lo artístico. No es propio que se este presenciando un drama pasional de emoción intensa, y estallen risas inoportunas, brillen en la sombrabra eigarros encendidos y suenen tazas, vasos y platillos en las mesas del rafé, yendo y viniendo los eamareros como en garito de feria en un pueblucho del eampo.

Es hora de evolucionar hacia el progreso. Tueumán es una ciudad acreedora a una representación apropiada a su cultura que todos reconocemos y admiramos, $y$ se hace preciso establecer allí eines con todos los adelantos de la época en que vivimos.

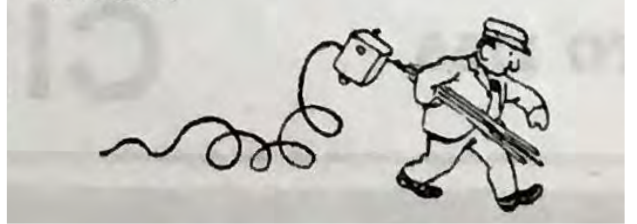

Fuente: La Película, Número 141, junio 1919. 


\section{El cine clásico industrial en las revistas especializadas en cine}

Entre los años 1933 y 1959 se desarrolla lo que se conoce, en la historia del cine argentino, como el período clásico-industrial de nuestra cinematografía. Dicho periodo comienza con el estreno de las primeras producciones sonoras iTango! (José Luis Moglia Barth, 1933) y Los tres berretines (Equipo Lumiton, 1933), y concluye a fines de la década del cincuenta, cuando el sistema se desploma a causa de la crisis institucional, política y social de la Argentina, ${ }^{34}$ que afectó gravemente a todos los sectores de la industria cinematográfica. Como resultante se produce el cierre de estudios y productoras, una baja en la realización de películas y la consecuente aparición de nuevas formas y estilos de realización independiente. Es en los años ' 30 - a partir de la articulación de la radio, el cine y el teatro- que se consolida la industria del espectáculo en Argentina. En ese contexto de ebullición, las revistas se convierten en el principal aliado de la industria, ocupándose de difundir las actividades y obras de cada medio, pero también exaltando la figura de las estrellas y enseñando a través de ellas conductas y modelos a imitar (Kriger, 2003). En este sentido, Eujanian (1999) aporta que los artistas, principalmente de cine, y el interés que los mismos despiertan fueron los que incentivaron la aparición de las revistas especializadas en el mundo del espectáculo. Asimismo, señala que en este periodo se produce un proceso de crecimiento del volumen de producción y variedad de publicaciones, dirigidas a un público heterogéneo, que es capturado mediante diversas estrategias comerciales y empresariales. En la amplia oferta gráfica del momento, encontramos revistas destinadas a un público popular, como las consultadas: Radiofilm, Sideral, Set, Magazine Cinematográfico y Primer Plano, que tenían como fin divulgar la actividad productiva de los estudios y los realizadores, pero también acompañar la actualidad de las personalidades del ambiente. Algunas de estas revistas, como Magazine Cinematográfico, se inclinaron por difundir en sus páginas información sobre el cine y las personalidades extranjeras, dejando solo apartados breves para las noticias nacionales. Por su parte, otras publicaciones como Set, Primer Plano o Radiofilm (en sus inicios) se concentraron en el mercado local. En todos los casos, el espacio reservado a las noticias en las regiones argentinas fue escaso, de poco desarrollo y precisión en sus contenidos, sin embargo, resultan muy útiles para mapear la actividad productiva en las provincias en este período.

La revista Radiofilm, como su título indica, es una publicación sobre los medios radial y cinematográfico. Su frecuencia era de emisión semanal por lo que se han consultado más de 250 números, editados a lo largo de 11 años. Esta publicación fue la que se encontró en mayor disponibilidad y acceso en nuestro relevamiento y es la que más información nos aportó. Allí, se divulgaban noticias de todo tipo en relación a la vida profesional y personal de los artistas, promoción de espectáculos, rodajes, carteleras, moda, concursos, festivales e información relevante sobre productoras, distribuidoras y salas de cine, entre otros temas. Dicho bagaje de información se encuentra organizado

${ }^{34}$ En el año 1955 tuvo lugar el golpe de estado autodenominado "Revolución libertadora" por parte del Ejército Argentino, encabezado por Eduardo Lonardi. Con este golpe, se derrocó al presidente constitucional Juan Domingo Perón, estableciéndose una dictadura cívico-militar que provocó un colapso institucional que afectaría a todos los estratos de la sociedad. 
en secciones como Qué me dice? de autoría de Mario Casal, Me han dicho que... firmada por Rondin, o Ellas, ellos y yo... a cargo de Elsa Quintana, donde se disponían notas sobre las personalidades del cine, la radio y el teatro en torno a sus actividades laborales y su vida privada. A su vez, en la sección denominada Cine al día, se concentra la mayor cantidad de noticias en relación a la cinematografía nacional, allí figuran los lanzamientos de estudios y las distribuidoras, los estrenos, la conformación de elencos y el avance de las filmaciones desarrolladas tanto en la ciudad como en las provincias. Esta sección a lo largo de los años cambia de nombre a Cine crítica y luego a Cine. Críticas y comentarios. En este apartado, se localiza la sub-sección Cinecosas donde se vierte una abundante cantidad de notas muy breves con información sumamente resumida. A pesar de lo sintético de las noticias, ese espacio resulta una fuente fecunda de información sobre las realizaciones y eventos cinematográficos argentinos donde frecuentemente se mencionan trabajos en las regiones. Es posible interpretar que el escaso espacio y desarrollo de las noticias provinciales se deba, en parte, a la falta de corresponsales y reporteros locales que prácticamente en ningún caso son mencionados ni destacados en la publicación. Otros apartados fijos dedicados al cine son Recorriendo los sets, Síntesis novelada y Recorriendo el mundo, este último basado especialmente en las figuras internacionales. Aparte de las secciones estables, se publican en todos los números notas de mayor desarrollo, que en muchas ocasiones abarcan más de una página completa, donde se resalta la figura de algún actor, músico o director, o bien, se destaca la realización de alguna producción nacional. Como la revista no es exclusivamente sobre el medio cinematográfico, también se encuentran sectores destinados al teatro y a la radio exclusivamente como Cocktail teatral y Cocktail de ritmos.

En los primeros años relevados, Radiofilm se caracteriza por tener un volumen amplio de noticias sobre cine nacional con algunas referencias al cine realizado en las provincias. Esta situación empieza a cambiar hacia 1955 en torno al golpe de estado, cuando las medidas impuestas por el gobierno peronista respecto a la protección a la industria del cine son retiradas, lo que implica un desfinanciamiento y deterioro del sistema productivo. ${ }^{35}$ En los años posteriores se ve reflejado el impacto político en el ambiente cinematográfico y aparecen plasmadas en la revista las discusiones y diversas opiniones de las personalidades de la industria sobre los problemas del medio. A partir del mes de enero de 1956 se pueden encontrar notas como la titulada "El cine argentino soporta ataques severos e injustos, afirma Soffici”. En su introducción ya puede leerse la explícita voluntad de la revista de hacer circular estas opiniones:

Siendo el problema del cine lo más importante en el momento actual en el medio artístico, hemos abierto una tribuna para que desde ella expresen sus puntos de vista todos aquellos que son figuras representativas de la incipiente industria. Comenzamos la edición anterior con Lucas Demare y continuamos hoy con

\footnotetext{
${ }^{35}$ En el catálogo Páginas de Cine (Kriger, 2003), Celeste Egea, a cargo de reseñar el semanario Radiofilm explica que alrededor del año 1949 la revista presenta una postura ideológica a favor del gobierno peronista, mientras que a partir de 1955 produce un vuelco ideológico hacia el régimen, que se manifiesta a través de la promoción de artistas como Arturo García Buhr en afinidad con la "Revolución Libertadora".
} 
la de otro celebrado director, Mario Soffici ${ }^{36}$.

Asimismo, se comienza a advertir un incremento de cine internacional en la cartelera y en la promoción de estrellas, por lo que el porcentaje de noticias sobre el cine europeo y hollywoodense llega a igualar o sobrepasar al del cine nacional. Ese mismo año, en una edición del mes de septiembre, puede observarse que las figuras destacadas en las notas principales son Vittorio Gassman, Greta Garbo y Clark Gable. A su vez, la tapa muestra a Martine Carol y Charles Boyer en ocasión de la promoción de la película Nana (Christian-Jaque, 1955), cuya historia ocupa, además, la sección Síntesis novelada ${ }^{37}$. En esta sección solían aparecer los estrenos argentinos, pero ahora el espacio comenzaba a poblarse de cine foráneo.

Figura 5. Tapas de revistas: Radiofilm, Magazine cinematográfico y Set
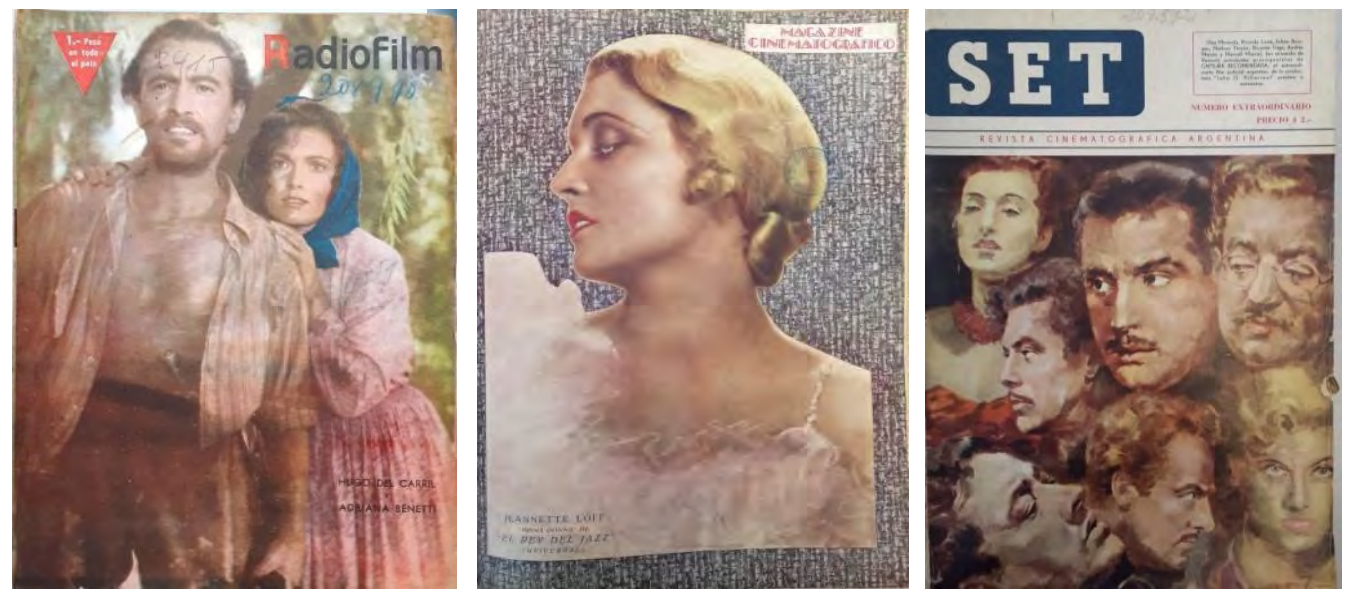

Existen además otras publicaciones dedicadas a la técnica y al quehacer práctico como Cine Mínimo. Todo lo referente al cine de 16, 9 y 1⁄2 y 8 milímetros y Cine técnica. Tratado técnico-práctico de cinematografía, ambas preocupadas por alcanzar un público aficionado a la praxis cinematográfica. Es posible encontrar en sus páginas artículos muy extensos y detallados sobre equipos de filmación, avances tecnológicos, fotografía, iluminación, sonido e información sobre el cine amateur, y sus producciones y rodajes a lo largo del país. En este momento nuestro cine se institucionaliza y sienta las bases de su industria, por lo que también hallamos ediciones que comunican la existencia y el progreso de nuevos organismos que surgieron como efecto de la instauración de esta nueva forma artística. Las revistas Boletín de la Academia de Artes y Ciencias Cinematográficas de la Argentina, Cine Club Argentino. Boletín mensual y Cosas de cine perteneciente a la Asociación Mutual Cinematográfica, actúan como ente de propaganda de las actividades de dichas agrupaciones y sociedades:

La Academia de Artes y Ciencias Cinematográficas da

\footnotetext{
${ }^{36}$ Radiofilm, $\mathrm{N}^{\mathrm{o}}$ 548, 11 enero 1956, p. 30-31.

${ }^{37}$ Radiofilm, No 583, 12 septiembre 1956.
} 
cumplimiento a uno de los mandatos de sus reglamentaciones sociales al iniciar la publicación de este Boletín. (...) el espíritu que la anima en esta empresa responde a su voluntad esencial de estimular el progreso técnico y artístico de la cinematografía en nuestro país, cada día más amplia y compleja en sus manifestaciones ${ }^{38}$.

En los últimos años se ha otorgado un especial interés al estudio de las publicaciones periódicas, ya que representan una enorme riqueza para el estudio de los procesos culturales, sociales e históricos de nuestro país. En tanto, las revistas especializadas en el medio cinematográfico nos permiten descubrir múltiples aspectos sobre el desarrollo del cine nacional. Kriger (2003) afirma que durante el período clásico industrial se consolida la industria cinematográfica argentina y las revistas dedicadas al medio juegan un rol decisivo en su afianzamiento, en relación a tres ejes principales: la formación de un star system, la intervención del Estado en la industria y el debate sobre que es el cine nacional. Asimismo, recalca que las revistas funcionan como registro del acontecer histórico, como documento de las relaciones de poder entre los distintos sectores de la industria, las empresas editoriales y el Estado. La prensa en general, y las revistas en particular, han transitado un camino en el que pasaron de ser vistas únicamente como fuentes documentales -y por lo tanto como medios- a ser consideradas un objeto de estudio en sí mismo (Pita González y Grillo, 2015), ideas que compartimos en este trabajo.

\section{Imágenes locales: producciones regionales}

Los autores Gámir Orueta y Valdés (2007) advierten la capacidad del cine como medio para retratar y describir los paisajes y a sus pobladores. Asimismo, proponen a este medio como un documento no sólo geográfico, sino también histórico-territorial, que nos permite reconstruir en la memoria aquellos espacios que ya no existen. La difusión de las imágenes captadas por el lente cinematográfico facilita una cierta democratización de lugares y paisajes antes inaccesibles, o incluso ignotos, para la mayor parte de la sociedad. A través de una lectura de las revistas del periodo hemos localizado un importante número de producciones filmadas en las provincias o con locaciones en ellas, que explotan los paisajes y territorios regionales como motivo visual. A su vez, relevamos la existencia de productoras regionales en distintos puntos del país y su intención de realizar películas en las provincias. Este hallazgo hace pensar, por un lado, en la existencia de distintos focos productivos lejos de la capital del país, empeñados en generar alternativas frente a la centralidad y exclusividad de Buenos Aires como único lugar para la producción de películas. Pero, por otro, también exhibe la pretensión de los realizadores de enseñar la identidad y las realidades locales. Se observa que, por lo general, las nacientes empresas regionales son exaltadas por los cronistas como verdaderas pioneras, valorizándose el esfuerzo que implica producir desde la periferia.

\footnotetext{
${ }^{38}$ Boletín de la Academia de Artes y Ciencias Cinematográficas de la Argentina, Nº 1 , septiembre 1942, p. 1.
} 
Grela Reina y Peterlini. El cine en las provincias argentinas desde las revistas porteñas.

Las dificultades en relación con la falta de experiencia y profesionalización técnica, pero también con la escasez de presupuestos, provoca que la vida de estos sellos se extinga rápidamente, llegando a producir, en algunos casos, una sola película.

Las realizaciones producto de estas innovadoras apuestas suelen ser la primera producción integral de su lugar de origen. En la revista del Cine Club Argentino se informa sobre la fundación de la empresa Cinematografía Payén, en la localidad de General Alvear (Mendoza), por un grupo de aficionados entre los que se encuentran Amado Sad y Atilio Piacenza, entre otros asociados. Como resultado de esta novedosa iniciativa se produce La chacra de Don Bautista (Atilio Piacenza, 1938), producción inaugural en cuyo rodaje tanto el capital técnico como artístico estuvo integrado por pobladores de la región. Así figuró el anuncio en la prensa de la época, luego del primer estreno de la compañía y en vísperas de una segunda realización: "Se ha formado un conjunto de aficionados bajo el nombre 'Cinematografía Payen' para producir películas amateurs de $16 \mathrm{~mm}$. (...) Auguramos un nuevo éxito a ese conjunto de entusiastas simpatizantes del Cine Club Argentino y esperamos poder exhibir su nueva película en nuestra pantalla" 39 .

Por su parte, de manera casi simultánea, en la ciudad de La Plata, se establece la firma X Film. Su aparición en el mercado fue destacada y celebrada por la revista Cosas de cine: "Ya contamos con una productora cinematográfica platense (...) La X Film, aspira a engrandecer su organización de principio modesta y sin grandes pretensiones de potencialidad industrial o artística. Simpático esfuerzo, es en concreto la nueva entidad productora" ${ }^{40}$. Su primera película, y la única que hemos podido localizar hasta el momento, se titula Sombra sobre el río (Juan Jacoby Renard, 1939) y es considerada como la producción inicial de la localidad. En tanto, en Chivilcoy surge el sello Estudios Cinematográficos Oeste Film que produce La sombra del pasado (Ignacio Tankel, 1946) y La tierra será nuestra (Ignacio Tankel, 1949). El rodaje de ambas películas se desarrolló en la localidad bonaerense y contó con la participación mixta de artistas locales y de la capital. En una nota de la época, se distingue la labor de la productora indicando que "una modesta empresa de tierra adentro se lanza a la conquista del público"¹.

En la provincia de Tucumán se realiza Mansedumbre (Pedro R. Bravo, 1952) El film posee un argumento confeccionado por el escritor local Guillermo C. Rojas y fue interpretado, en parte, por actores de la propia provincia. La productora tucumana a cargo de su realización aparece nombrada en la revista Radiofilm, a partir de algunas notas difusas desde el año 1950, en un primer momento denominada Kine-Rector y luego como Kine-Rector Pronorte. ${ }^{42}$ El mismo medio difunde varias noticias, ligadas al proceso de realización de la película, hasta el momento de su estreno, ocasión en la que se publica una extensa nota que destaca el contexto regionalista que encierra la producción, pero

\footnotetext{
${ }^{39}$ Cine Club Argentino. Boletín mensual, № 6, septiembre 1941, s/p.

${ }^{40}$ Cosas de cine $\mathrm{N}^{\circ} 14$, julio 1938, p. 13.

${ }^{41}$ Radiofilm, $\mathrm{N}^{\circ} 213,10$ agosto 1949, p. 23.

${ }^{42}$ Los autores Azcoaga y Ovejero (2014) sostienen que son dos compañías diferentes, Kine-Rector Cine Productora Argentina y Pro-Norte Producciones Cinematográficas, las responsables de la financiación y producción de la película.
} 
también su capacidad como competidora en un mercado exigente: “Cañaverales de azúcar, cerros, caminos y vegetación exuberante constituyen los marcos centrales de la primera superproducción tucumana que entra a competir firmemente con el cine de capital"43. En otra latitud, en la ciudad de Mendoza, surge la productora independiente Hernández Film, que realiza en los estudios de Andes Film — por no tener estudios propios- la película Acorralada (Julio C. Rossi, 1953) ${ }^{44}$. Por último, ubicamos la realización de la película Continente blanco (Bernard Roland, 1957), también llamada Operación Antártida, a cargo del sello Mar del Plata Films, perteneciente a la ciudad balnearia ${ }^{45}$.

A menudo, la mirada de la capital sobre estos fenómenos ocurridos en las provincias no oculta su asombro al observar la concreción de proyectos locales, como si fuesen pequeñas hazañas para estas nacientes empresas. Respecto de la realización de Mansedumbre, la revista Radiofilm manifiesta: "Los periodistas porteños pudieron ver cómo sin galerías ni medios técnicos adecuados los entusiastas cinematografistas tucumanos realizaron una película noble y digna que, en la noche de la première, mereció el aplauso cálido y espontáneo de los críticos y del público que rebalsaba la sala del Cine Plaza." ${ }^{46}$.

En cuanto a productoras regionales, existe un caso que se distingue del resto, Film Andes. ${ }^{47}$ Mientras los anteriores ejemplos refieren a compañías que duraron muy poco, y cuya producción se limita a unas pocas películas, la productora Film Andes presenta una supervivencia de más de una década y una prolífica lista de películas. Entre los años 1944 y 1956, Mendoza fue escenario de una experiencia inédita en el interior del país: la empresa de capitales locales realizó 15 largometrajes en un proceso único en el campo de las industrias culturales regionales (Ozollo, 2004). Las películas de este sello tienen amplia cobertura en las revistas y son objeto de múltiples notas, en las que usualmente se refleja el estado de avance de las realizaciones, las contrataciones de artistas y las jornadas de filmación en exteriores. El tono con el que se redactan las noticias desde la ciudad capital suele estar en relación con el atractivo local y turístico de los territorios registrados por la cámara de los cineastas. Pocas veces puede trascender la centralidad de su mirada porteña. Esto se aplica claramente en la difusión de la película Lejos del cielo (Catrano Catrani, 1950), que fue promocionada por la prensa como la primera producción de Film Andes en rodarse íntegramente en Mendoza, en los estudios levantados por la compañía en la localidad de Godoy Cruz. En una de las notas localizadas respecto del film se destaca que "la naturaleza extraordinaria de la fértil provincia colabora, por así decirlo, con esta producción" ${ }^{48}$. El mismo matiz se empleó para referirse a Rescate de sangre (Francisco Mugica, 1951) de la que se subraya, también, la relevancia del espacio capturado: "Las escenas de esta película fueron filmadas en pleno macizo andino, cuya belleza ha sido hábilmente aprovechada

${ }^{43}$ Radiofilm, No 292, 14 Febrero 1951, p. 26.

${ }^{44}$ Radiofilm, No 302, 25 abril 1951; Set, No 29, agosto 1951.

${ }^{45}$ Radiofilm, No533, 28 septiembre 1955

${ }^{46}$ Radiofilm, No 362, 18 junio 1952, p. 21.

47 Sobre Film Andes, Hopfenblatt (en este número) presenta un trabajo exhaustivo sobre la empresa.

${ }^{48}$ Radiofilm, $\mathrm{N}^{\circ} 257,14$ junio 1950, p. 23. 
por un joven y audaz fotógrafo: Andrés Marterell"49. Los adjetivos en torno a la belleza natural se repiten en todas las notas y las categorías de colorido y pintoresco suelen estar presentes en los textos.

En el caso de La pícara cenicienta (Francisco Mugica, 1951), en cambio, se elige exaltar la importancia de la producción como una oportunidad artística para los pobladores de la provincia: "excelente oportunidad para triunfar en el cine, porque, en efecto, el director Francisco Mugica, luego de completar el elenco estelar (...) ha contratado a aficionados locales" ${ }^{50}$. El desembarco de una empresa cinematográfica en cualquier localidad significa la generación de distintas fuentes de trabajo para artistas, técnicos, auxiliares y comerciantes que se ven empleados en relación a la producción de películas.

Además, muchas producciones de Film Andes son promovidas por la prensa porteña debido a la participación de estrellas nacionales resonantes: actores, músicos, directores y guionistas. Sobre Un ángel sin pudor (Carlos Hugo Christensen, 1953) los medios resaltan la contratación de la renombrada actriz Susana Freyre ${ }^{51}$. Mientras que para El último cowboy (Juan Sires, 1954) señalan la participación del actor Augusto Codecá y del director Juan Sires ${ }^{52}$. En el caso de El cartero (Homero Cárpena, 1954), la dirección y actuación de Homero Cárpena ${ }^{53}$. Y sobre El mal amor (Luis Mottura, 1955) la promoción estuvo vinculada a la pareja protagónica compuesta por Mecha Ortiz y Ricardo Passano ${ }^{54}$.

En el año 1954, cuando comienzan a profundizarse los problemas en la industria cinematográfica a nivel nacional, aparecen en Radiofilm comentarios acerca de la realización de Surcos en el mar (Kurt Land, 1956), film que significa el último hito de Film Andes. La revista destaca la temática en torno a la historia de la Marina Mercante Argentina y realza la película por la belleza de los paisajes de la provincia de Mendoza:

'La realización de 'Surcos en el mar' importa una empresa de producción de gran aliento, que ha acometido Film Andes con el propósito de hacer una película de verdadera categoría. Uno de los aspectos que en este sentido debe destacarse es la variedad e interés de sus escenarios naturales" ${ }^{\prime 5}$.

Rodada en Potrerillos, Uspallata, en la zona cordillerana, en el puerto de Chile, en Buenos Aires y a bordo de la embarcación petrolera argentina Comodoro Rivadavia, hace gala de un gran despliegue visual y representa una arriesgada apuesta económica para la compañía. En este sentido, Javier Ozollo (2004) apunta que es la última producción realizada totalmente con capitales mendocinos de Film Andes y sostiene

\footnotetext{
${ }^{49}$ Radiofilm, No 371, 20 agosto 1952, p. 23.

${ }^{50}$ Radiofilm, No 291, 7 febrero 1951, p. 22.

${ }^{51}$ Radiofilm, No 379, 15 octubre 1952.

${ }^{52}$ Radiofilm, No 406, 22 abril 1953.

${ }^{53}$ Radiofilm, No 420, 29 julio 1953.

${ }^{54}$ Radiofilm, No 437, 25 noviembre 1953.

${ }^{55}$ Radiofilm, $\mathrm{N}^{\circ} 468,30$ junio 1954, p. 28
} 
que probablemente esta película haya sido una de las más maduras, con un excelente desarrollo técnico de la época.

Por último, en este período, al igual que sucedió durante el cine silente, destacamos la existencia de los auspicios provinciales como otra de las formas e iniciativas que contribuyeron al desarrollo del cine en las provincias. Esta colaboración se encuentra mencionada claramente en una noticia de 1949: "Con Amanda Varela y Francisco de Paula en los roles protagónicos, se inició en la provincia de Tucumán el rodaje de 'El diablo de las vidalas', bajo la dirección de Belisario García Villar y con auspicios de la Universidad Nacional que funciona en esa provincia." ${ }^{56}$. El Instituto Cinematográfico de la Universidad Nacional de Tucumán tenía entre sus principales objetivos la formación en fotografía y cinematografía, así como el favorecer la realización de cortos y largometrajes, especialmente de contenido científico, didáctico y de divulgación popular. La creación de un instituto con tales características representó un proyecto original para las universidades del país (Azcoaga y Ovejero, 2014) y un impulso para las cinematografías regionales.

\section{Avant-Premières y salas provinciales}

Resulta interesante observar las prácticas de exhibición y los estrenos en las salas ubicadas en las provincias argentinas durante el período clásico-industrial. Aunque en la prensa publicada en la Ciudad de Buenos Aires (objeto de esta investigación), no figuran las carteleras completas de cada sala regional o provincial, situación que permitiría un estudio más acabado de la realidad cinematográfica del país, sí se encuentran algunos espacios extraordinarios destinados a anunciar la proyección de algunas películas. Esta información podría favorecer la elaboración de un panorama sobre cuáles eran los materiales que llegaban desde Buenos Aires y los gustos y preferencias que tenían los espectadores de las provincias. Desde ya, esta es una mirada filtrada por los intereses de editores porteños quienes decidían a qué evento dar relevancia a través de la promoción en las revistas.

Un fenómeno que se destaca son las presentaciones o Avant-Premières de películas en localidades provinciales. Una cantidad de films fueron exhibidos por primera vez en una pantalla regional, antes de ser mostrados en los cines de la capital, destino prometido para todas las producciones argentinas. Estos casos excepcionales fueron especialmente destacados por la revista Radiofilm donde se divulgaban notas en las que se mencionan los títulos de estreno, pero también solían dar cuenta del desplazamiento de artistas, directores, representantes de los estudios, productores y críticos a la ciudad de la Première. La presencia de estrellas y figuras del espectáculo revestían el evento de gran atractivo, y convocaban amplia cantidad de público a las salas. Este fue el caso de Danza de fuego (Daniel Tinayre, 1949), que se exhibió en Mendoza y en San Juan a modo de anticipo de su estreno porteño:

Anticipándose al estreno que en estos días se llevará a cabo

\footnotetext{
${ }^{56}$ Radiofilm, $\mathrm{N}^{\circ}$ 232, 21 diciembre 1949, s/d.
} 
en Buenos Aires, Emelco e Interamericana proyectaron en San Juan y Mendoza la película "Danza de fuego", que dirigida por Daniel Tineyre, tiene a Amelia Bence de protagonista. Un público entusiasta - que expreso a viva voz su satisfacción no solo por la primicia, sino por los méritos de la producción - se hizo presente en las salas de las dos capitales donde se exhibió "Danza de fuego". 57

En tanto, La barca sin pescador (Mario Soffici, 1950) fue estrenada en Córdoba y contó con la presencia de su actor principal, Pedro López Lagar y de su director Mario Soffici ${ }^{58}$.

Los estrenos en las provincias, frecuentemente, se encuentran ligados a películas que habían sido rodadas en el lugar a exhibirse. El público local, por el despliegue que significa el rodaje de una película en una ciudad provincial, probablemente conocía detalles acerca de la realización y eso resultaba un incentivo. A su vez, congregaba a espectadores ávidos de ver su lugar de origen reflejado en la pantalla. Ese nexo, podría explicar la decisión de programar un lanzamiento lejos de Buenos Aires. Esto puede observarse en algunos de los estrenos en salas regionales del período clásico industrial tales como La última escuadrilla (Julio Saraceni, 1951), que se efectuó en la ciudad de Córdoba y cuya filmación se llevó a cabo totalmente en dicha ciudad resultando un gran éxito $^{59}$. La película Stella Maris (Homero Cárpena, 1952), a propósito de la Semana del Mar, se estrenó en el cine Atlantic de Mar del Plata ${ }^{60}$. Mientras que, a su vez, Tucumán tuvo la primicia de Mansedumbre (Pedro R. Bravo, 1953) en el Cine Plaza ${ }^{61}$. Por su parte, la ciudad de Mendoza fue la sede de La noche de Venus (Virgilio Muguerza, $1955)^{62}$ y de Surcos en el mar (Kurt Land, 1956) ${ }^{63}$. Por último, Cerro Guanaco (José Ramón Luna, 1959) se vio por primera vez en Catamarca:

Las empresas de producción de "Cerro guanaco", Alipa Cinematográfica de esta capital y Cinematográfica Achalay de la provincia de Catamarca, anuncian que el estreno mundial de esa película se realizará en Catamarca, mañana 27 de agosto. Esta primicia que tomará carácter de fiesta, es ofrecida por sus productores como adhesión a los grandes actos programados en la "Semana de la Autonomía de Catamarca". "Cerro guanaco" fue filmada íntegramente en esa provincia ${ }^{64}$.

\footnotetext{
${ }^{57}$ Radiofilm, $\mathrm{N}^{\circ} 230,7$ diciembre 1949, s/d.

${ }^{58}$ Radiofilm, $\mathrm{N}^{\circ} 240,15$ febrero 1950.

${ }^{59}$ Radiofilm, $\mathrm{N}^{\circ} 328,24$ octubre 1951

${ }^{60}$ Radiofilm, $\mathrm{N}^{\circ} 377,1$ octubre 1952.

${ }^{61}$ Radiofilm, $\mathrm{N}^{\circ} 362,18$ junio 1952.

${ }^{62}$ Radiofilm, $\mathrm{N}^{\circ}$ 502, 23 febrero 1955.

${ }^{63}$ Radiofilm, N 542, 20 noviembre 1955.

${ }^{64}$ Radiofilm, No 737, 26 agosto 1959, p. 50.
} 
Estas proyecciones suelen ser informadas por la prensa una sola vez, lo que imposibilita rastrear el tiempo de permanencia de la película en cartel, dato que se revela como imprescindible a la hora de dar cuenta del éxito y acogida del público regional.

Figura 6. La noticia de página completa refiere al estreno, en la ciudad de Córdoba, de la película La barca sin pescador (Mario Soffici, 1950)

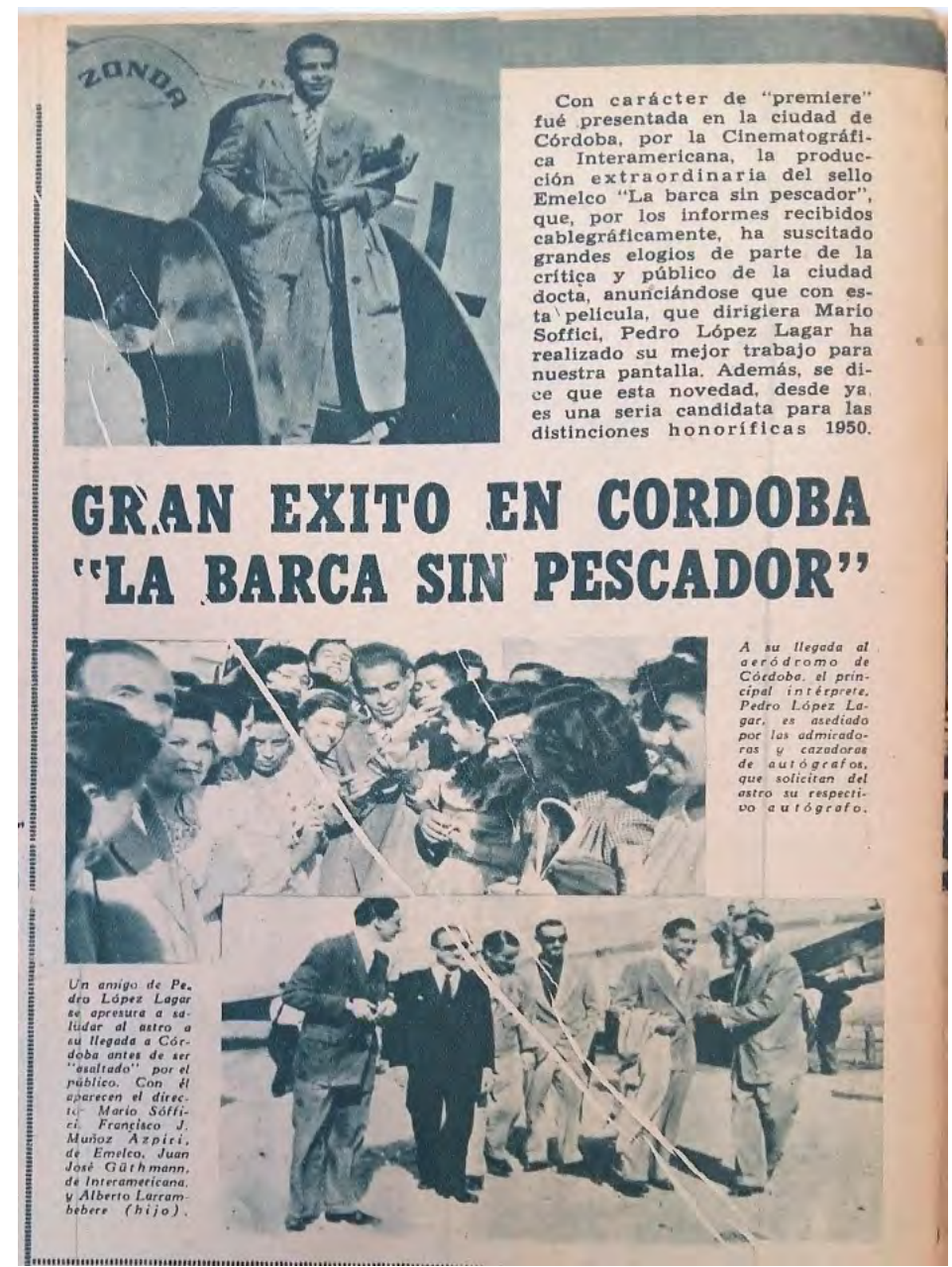

Fuente: Radiofilm, № 240, 15 febrero 1950. 
Grela Reina y Peterlini. El cine en las provincias argentinas desde las revistas porteñas.

Figura 7. Noticia a propósito del estreno de Mansedumbre (Pedro R. Bravo, 1953), rodada y exhibida por primera vez en la provincia de Tucumán

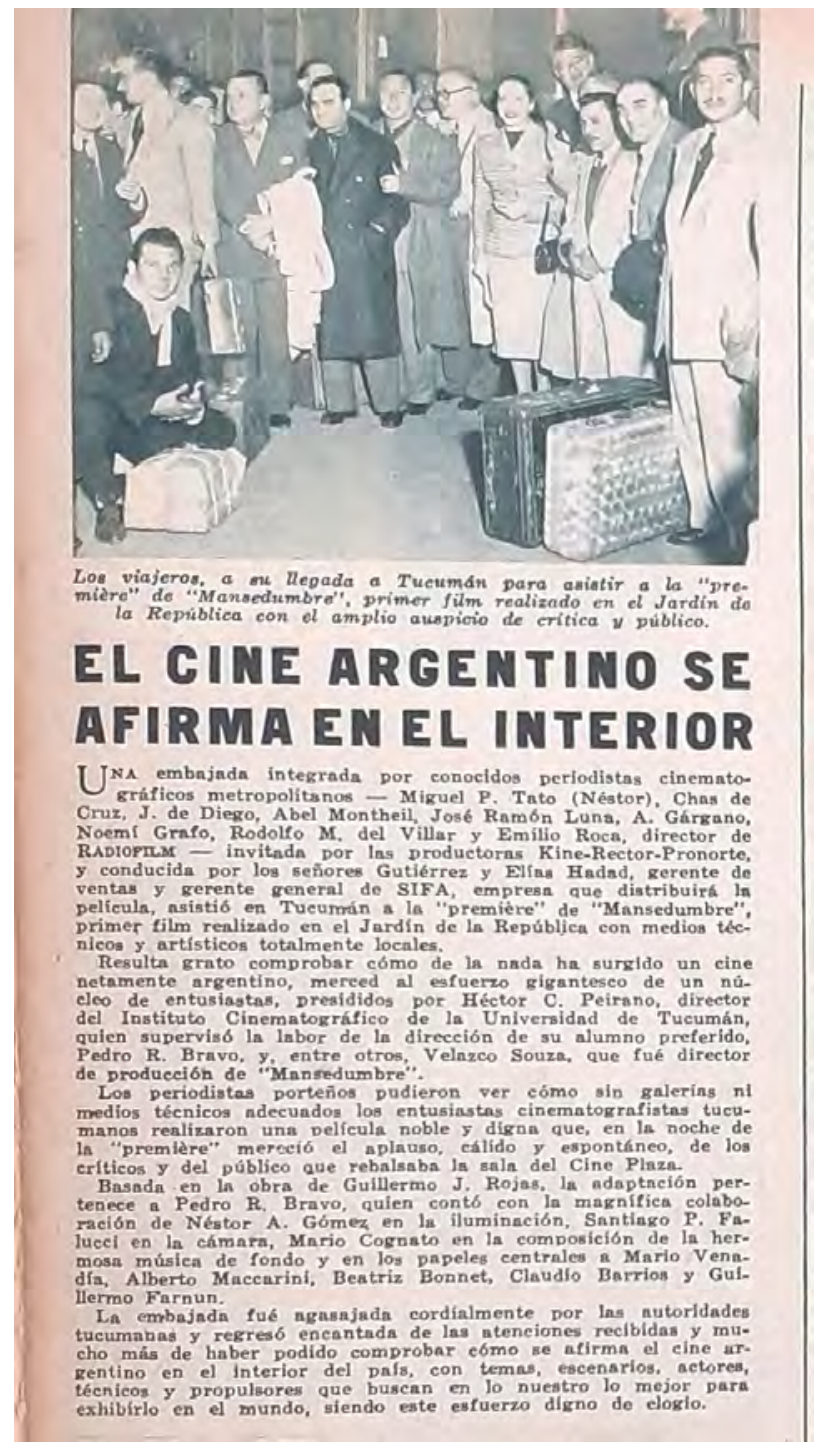

Fuente: Radiofilm, №362, 18 junio 1952.

Las páginas de las revistas de cine también se encargaron de mostrar las exhibiciones en salas del país de películas argentinas producidas y ya estrenadas en la capital que luego se dirigían hacia las provincias en busca de la explotación de nuevos públicos. La ciudad de Mar del Plata es uno de los lugares más renombrados en las publicaciones periódicas, en cuanto a estrenos. Un claro ejemplo es la promoción de la película Arrabalera (Tulio Demicheli, 1950), para la cual la prensa no sólo difundió el debut del film en la localidad costera, sino que además destacó la presencia de la actriz y 
protagonista Tita Merello en su primera función ${ }^{65}$. A su vez, la apertura de la temporada de verano y la consecuente afluencia de turistas se presenta como una oportunidad para lanzamientos. Con esa excusa, en 1952 se estrena de La encrucijada (Leopoldo Torres Ríos, 1952): “Ha sido recibida con beneplácito por el público que disfruta el verano en Mar del Plata, la película que protagonizó Ricardo Trigo para la productora Independiente Argentina, 'La encrucijada' que se estrenó el jueves anterior" ${ }^{\prime \prime}$.

Por su importancia como centro turístico y zona de recreación, la localidad de Mar del Plata es foco de frecuentes menciones en las revistas de la Capital, ya sea en relación al mantenimiento e innovación en las salas como a la apertura de nuevos salones. A modo de ejemplo, se menciona la presentación del sistema VistaVision en salas de Mar del Plata, iniciativa que fue celebrada por el público y la prensa ${ }^{67}$ y el anuncio, en 1957, de la apertura de "la sala de exhibición más grande de Mar del Plata Gran Cine Nogaró, cuya capacidad contempla alrededor de 2800 espectadores" $" 68$.

Además de Mar del Plata, los medios gráficos porteños señalan otros centros de exhibición en diversos puntos de la Argentina. En la ciudad de Mendoza tuvo lugar la proyección de El seductor (Luis Bayón Herrera, 1950) ${ }^{69}$ y en Tucumán se estrenó

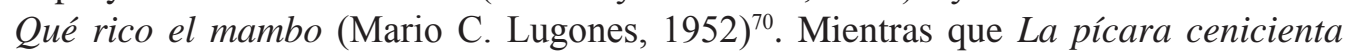
(Francisco Mugica, 1951) de Film Andes se anuncia en las ciudades de Mendoza, Córdoba, San Juan, Santa Fe y Rosario ${ }^{71}$; y Las aguas bajan turbias (Hugo del Carril, 1952) en las localidades de Tucumán, Córdoba, San Francisco, Rio Cuarto, Villa María, Mendoza, San Rafael y San Juan ${ }^{72}$.

\section{Los festivales de cine en Mar del Plata y Río Hondo a través de la óptica de la ciudad}

Los festivales de cine aparecen en el mundo cuando la industria cinematográfica ya se encuentra sólidamente establecida. El Festival Internacional de Cine de Venecia tuvo su primera edición en el año 1932 y es considerado el festival de cine más antiguo del mundo. El Festival de Cannes se realizó por primera vez en 1946, a pesar de estar programado inicialmente en 1939. A su vez, el Festival Internacional de Cine de Berlín nació en 1951. Al respecto, Alonso (2018) afirma que en esta primera etapa los festivales fueron organizados por una combinación de motivos económicos, turísticos, políticos — geopolíticos- y culturales. Al mismo tiempo, constituían un mecanismo de difusión de los films, como así también de políticas y culturas nacionales. Asimismo, Campos (2018) sostiene que en esta etapa inicial el circuito de festivales era considerado como un tiempo de "olimpiadas cinematográficas", ya que eran entendidos como "Exposiciones

\footnotetext{
${ }^{65}$ Radiofilm, $\mathrm{N}^{\circ} 248,12$ abril 1950.

${ }^{66}$ Radiofilm, $\mathrm{N}^{\circ} 340,16$ enero 1952, p. 16.

${ }^{67}$ Radiofilm, No 554, 22 febrero 1956.

${ }^{68}$ Radiofilm, No 602, 23 enero 1957, p. 34.

${ }^{69}$ Radiofilm, $\mathrm{N}^{\circ} 246,29$ marzo 1950.

${ }^{70}$ Radiofilm, $\mathrm{N}^{\circ} 334,5$ diciembre 1951.

${ }^{71}$ Radiofilm, $\mathrm{N}^{\circ} 313,11$ julio 1951.

${ }^{72}$ Radiofilm, N 378,8 octubre 1952.
} 
Grela Reina y Peterlini. El cine en las provincias argentinas desde las revistas porteñas.

Universales en las que se ofrecía una muestra del arte realizado en diferentes partes del mundo" (p. 17). Además, como antecedente a lo sucedido con posterioridad en el escenario local, resulta importante destacar la tensión y vínculo existente entre Europa y América Latina. En relación a esto, Campos señala el peso de los festivales europeos -en tanto centros de la cinematografía mundial, con poderosas instituciones - sobre el resto de las cinematografías del mundo, entre las que se incluye la argentina. Señalamos, por último, la incidencia de los estados y cuerpos diplomáticos en la organización de los festivales de cine en el mundo, como así en la selección y programación de los mismos $^{73}$. Este influjo se observará de manera clara en la primera edición del Festival Internacional de Cine de Mar del Plata.

La industria cinematográfica nacional pronto forma parte del circuito de festivales, haciendo uno de sus primeros ensayos en el año 1948 a través de la muestra cinematográfica, no competitiva ni tampoco internacional, desarrollada en la ciudad de Mar del Plata ${ }^{74}$. Unos años después, en 1954, y por impulso de las políticas del gobierno peronista, se realizó el primer Festival Internacional de Cine, en la misma ciudad. En Radiofilm inmediatamente se impulsó una campaña de difusión y promoción que incluyó noticias como la titulada "El festival de cine se está organizando", donde se observa claramente la relevancia que se le otorga al festival y la colaboración nacional y provincial en la organización del evento:

La Subsecretaría de Informaciones de la Presidencia de la Nación, comenzó a organizar el Festival Internacional de Cine que se iniciará en Mar del Plata en la primera quincena de marzo y finalizará en la capital, contando con la colaboración del gobierno de la Provincia de Buenos Aires. A la extraordinaria muestra, concurrirán embajadas de los Estados Unidos, Francia, México, Italia, Gran Bretaña y España ${ }^{75}$.

Kriger (2004) explica que el festival, en su primera edición, logró el reconocimiento de la Federación Internacional de Asociaciones de Productores de Films (FIAPF), que le otorgó la categoría B (internacional y sin premios), misma condición a la que pertenecían los certámenes anuales de San Pablo, Berlín y San Sebastián. En sus ediciones posteriores el festival obtuvo la valiosa categoría "A", máximo rango que puede recibir un evento de estas características, siendo al día de hoy el único festival de cine latinoamericano que reviste esa denominación. Siguiendo las ideas de Kriger, entendemos que la elección de la localidad de Mar del Plata como sede del festival no fue azarosa. Por el contrario, se basó en una serie de decisiones en relación a la ciudad balnearia como máximo destino turístico y exponente simbólico peronista: "Cine y política se dieron cita en la playa del Atlántico que había dejado de ser a principios de los años cuarenta la antigua villa veraniega de la elite social, para convertirse en un

\footnotetext{
${ }^{73}$ La investigadora Campos (2018) aporta que desde el origen de los festivales hasta el año 1968, las películas eran preseleccionadas por los cuerpos diplomáticos y culturales de cada país postulante.

${ }^{74}$ Cine Mínimo, № 1, mayo 1948.

${ }^{75}$ Radiofilm, N²46, 9 septiembre 1953, p. 22.
} 
balneario de masas durante el peronismo. Un espacio ideal para aglutinar el espectáculo y la política, con el objetivo de optimizar réditos para ambos campos" (Kriger, 2004, p. 119). El evento despertó la expectativa del público y la atención de la prensa que se refirió a él como una cabal expresión del progreso del arte y la técnica cinematográfica ${ }^{76}$. En simultáneo, se reflejó el entusiasmo por la llegada y participación de las principales personalidades artísticas internacionales y nacionales. Así lo demuestra una noticia en torno a la visita de Chaplin ${ }^{77}$ al festival: "Entre las famosas luminarias que nos visitaran se adelanta que se hará presente el genial bufo Charles Chaplin, lo cual constituirá una nota de excepcional atracción y jerarquía en dicho festival y para nuestro público"78.

Luego de esa edición hubo una interrupción a causa del golpe de estado de 1955 al gobierno de Juan D. Perón. La consecuente crisis en que se hundió la Argentina no dejó al margen a la industria cinematográfica, produciéndose un intervalo que acabó en el año 1959 cuando retorna el Festival Internacional de Cine de Mar del Plata. Durante mucho tiempo, la edición del año 1954 fue negada a causa de la proscripción del peronismo. Recién en 1996 se recuperó este antecedente y se sumó a la cuenta oficial de ediciones. La celebración del nuevo festival fue promovida ampliamente desde las revistas especializadas, donde se destaca que los organizadores se encontraban enfocados en posicionar la ciudad de Mar del Plata como lugar de referencia:

La Asociación de Cronistas Cinematográficos de la Argentina se halla abocada al estudio de un proyecto muy ambicioso, consiste en lograr que Mar del Plata pueda convertirse en el futuro en un gran centro de Festivales Internacionales, contando para ello en primer lugar, con el apoyo de las autoridades nacionales, provinciales y municipales y de organismos como la Dirección Nacional de Lotería de Beneficencia y Casinos. Ojalá la idea cristalice y sirva para promover el intercambio de nuestras películas ${ }^{79}$.

Además, en la lectura de esta noticia se observa que el Festival está organizado por la Asociación de Cronistas Cinematográficos, lo cual imprime al evento un temple distinguido por su vinculación con la crítica especializada. A tono con la época, el certamen se alinea con la aparición de las nuevas olas cinematográficas surgidas en Europa y afianzadas (en parte) por las revistas de crítica de cine. En este sentido, Triana Toribio (2007) afirma que este grupo de críticos al frente del Festival, admiraba los nuevos cines y estaba deseoso de traerlos al país. Por lo que esta asociación se preocupó de distanciar el evento de la acusación de frivolidad. Como parte de la cobertura, resulta muy interesante observar la declaración de aspiraciones del festival, vertida por la Asociación de Cronistas en la revista Radiofilm. La lista presenta los

\footnotetext{
${ }_{76}$ Radiofilm, No440, 16 diciembre 1953.

${ }^{77} \mathrm{La}$ presencia del actor internacional Charles Chaplin, finalmente, no se concretó en la mencionada primera edición del festival.

${ }^{78}$ Radiofilm, No440, 16 diciembre 1953, p. 20.

${ }^{79}$ Radiofilm, $\mathrm{N}^{\circ} 697,19$ noviembre 1958, s/d.
} 
siguientes objetivos: "a) hacer conocer la industria fílmica argentina en el mundo; b) que Mar del Plata, al igual que Cannes y Venecia, se convierta en un lugar de turismo y atracción universal, c) promover una corriente cinematográfica universal hacia nuestra industria" ${ }^{80}$. Esta clara exposición demuestra su importancia para la industria y para la región, en tanto zona de explotación turística que espera equipararse con las principales sedes de festivales de cine en el mundo. La revista exprimió el vital acontecimiento para llenar las páginas de su publicación, por lo que no resulta extraño encontrar notas como la titulada "Hoy comienza la fiesta del cine" donde se destinan dos pliegos para informar las fechas, horarios, lugares de exhibición, personalidades que concurren y actividades destacadas ${ }^{81}$. Las pantallas de los festivales se constituyen como una valiosa alternativa para películas nacionales e internacionales que encuentran posibilidades de exhibición en espacios diferentes de las salas tradicionales y, a su vez, colaboran en la circulación y distribución de films comerciales y experimentales.

Figura 8. Noticia sobre la cobertura del segundo Festival Internacional de Cine de Mar del Plata

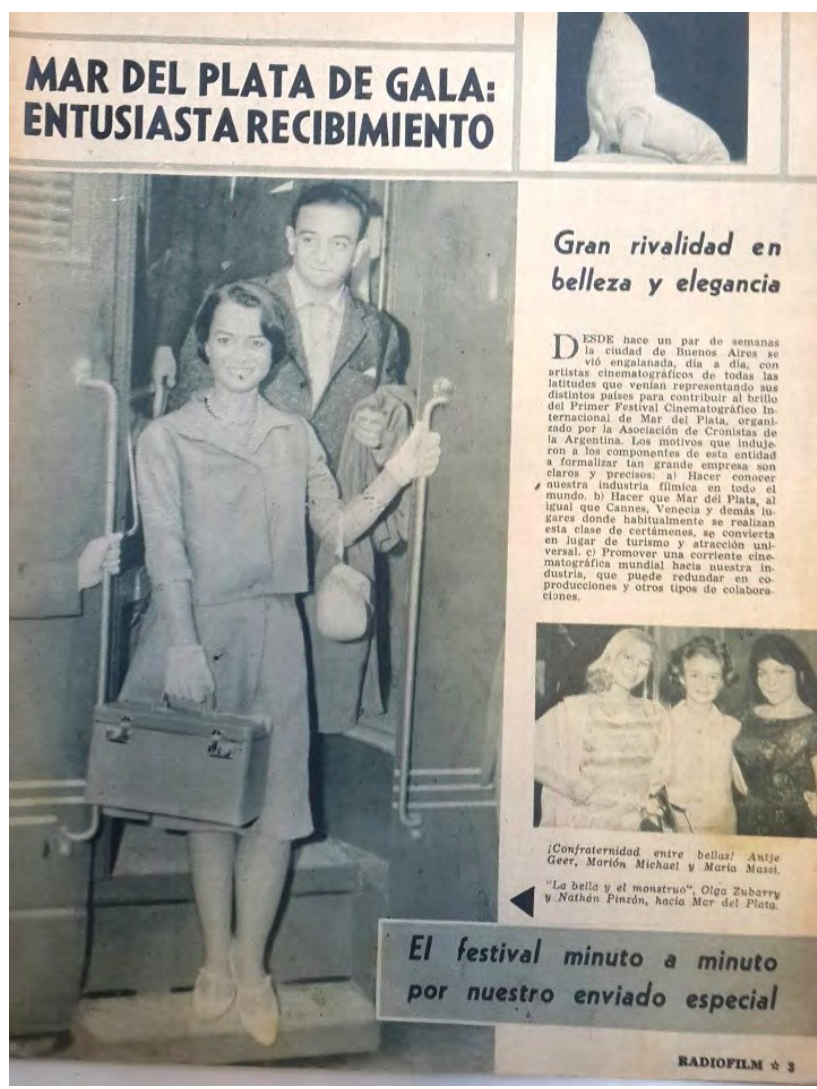

Fuente: Radiofilm, N 714, 18 marzo 1959.

\footnotetext{
${ }^{80}$ Radiofilm $\mathrm{N}^{\circ} 714,18$ marzo 1959, p.3
}

${ }^{81}$ Radiofilm, № 713, 11 marzo 1959. 
Figura 9. Noticia sobre la apertura del segundo Festival de Cine de Río Hondo

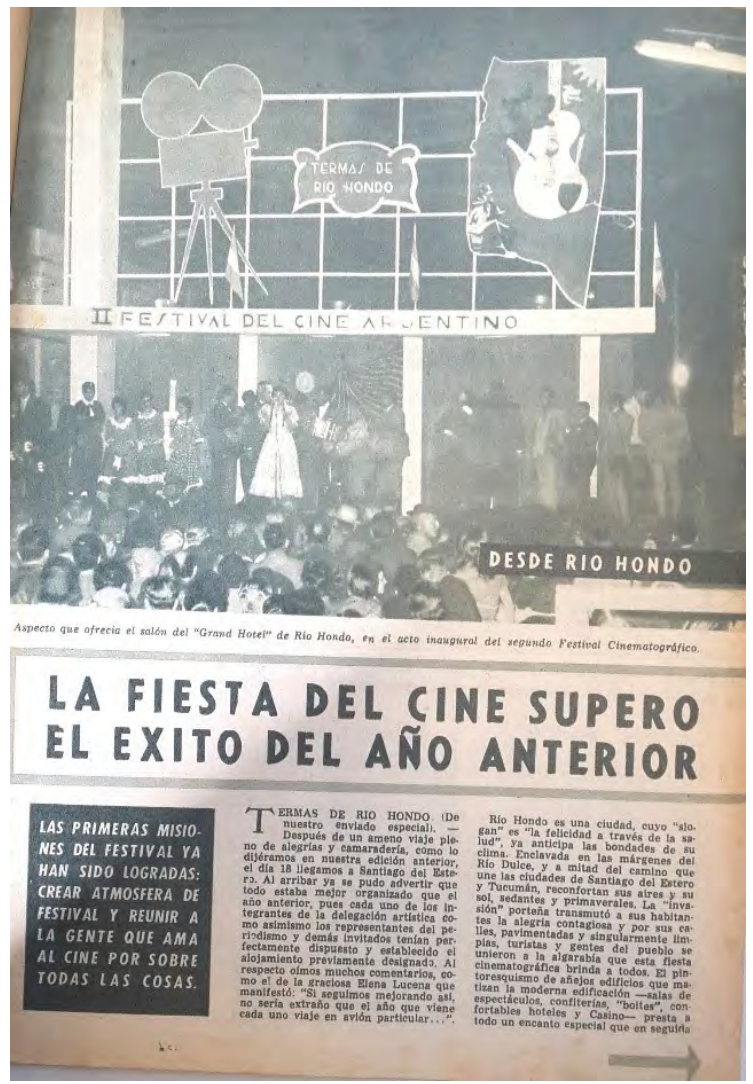

Fuente: Radiofilm, N 729, 19 julio 1959.

En ese mismo año, en Santiago del Estero, se anuncia la realización del segundo Festival de Cine de Río Hondo, ${ }^{82}$ auspiciado por el gobierno de la provincia. En una extensa nota publicada en la revista Radiofilm en el mes de abril de 1959 se detalla la organización como así sus características y propósitos:

Auspiciado y patrocinado por el Gobierno de Santiago del Estero se realizará, entre los días 19 y 28 de junio, en Termas de Río Hondo, el Segundo Festival de Cine Argentino. La comisión organizadora se integra con representantes de todas las ramas de la industria cinematográfica, incluido el periodismo especializado. El certamen básicamente estará destinado a valorizar los 30 años del cine argentino que van desde 1928 a 1959 . Se votarán 15 a 20 películas de este periodo y los votos se verán vertidos por todos los invitados al festival.

\footnotetext{
${ }^{82}$ En las publicaciones periódicas consultadas no hemos podido localizar noticias sobre la realización del primer festival de cine de Río Hondo del año 1958.
} 
Grela Reina y Peterlini. El cine en las provincias argentinas desde las revistas porteñas.

De este modo se obtendrá una valorización total del periodo más importante de nuestra cinematografía. No habrá premios para las películas que se exhiban. Paralelamente se efectuará un concurso de films de corto metraje con tres premios, el primero de los cuales estará presentado por la estatuilla Homero Manzi, ya instituida en el certamen del año pasado ${ }^{83}$.

Como puede observarse, la muestra tuvo fines publicitarios para películas nacionales y para los agentes y personalidades del ambiente. Alrededor de este acontecimiento cinematográfico inigualable para la provincia se organiza una amplia cobertura en la revista Radiofilm. Es posible encontrar por lo menos siete números ${ }^{84}$ en los que se informa, semana tras semana, sobre los preparativos, viajes, jornadas, actividades, actores, directores, distribuidores y representantes de la industria en relación al festival. En los meses precedentes al evento se observan comentarios en relación a la generosidad de la región y a sus bondades turísticas: "Río Hondo es una ciudad, cuyo 'slogan' es 'la felicidad a través de la salud', ya anticipa las bondades de su clima. Enclavada en los márgenes del Río Dulce, y a mitad del camino que une las ciudades de Santiago del Estero y Tucumán, reconfortan sus aires y su sol, sedantes y primaverales" ${ }^{\prime 5}$. Asimismo, se resalta la alegría con la que se espera al público porteño y a los artistas más reconocidos de la escena local; el festival se presenta sintéticamente como una fiesta para la gente que ama al cine ${ }^{86}$. La difusión fue tan marcada que es factible deducir el interés que despertaba, tanto en los espectadores como en los productores y empresarios de la industria del espectáculo. Su resonancia fue tal que inclusive se transmitió especialmente desde Termas de Río Hondo para todo el país, a través de la frecuencia de Radio Belgrano a fin de actualizar los principales sucesos del festival ${ }^{87}$. La exitosa realización de esta edición, y el interés generado, posibilitó proyectar un crecimiento del festival. Tal es así que el gobernador de la provincia, Eduardo Miguel, informó que el año entrante se elevaría el carácter del festival de nacional a latinoamericano ${ }^{88}$.

Es notable que revistas de la Capital destinen espacio tan voluminoso a eventos realizados en el territorio argentino. El caso de los festivales de cine de Mar del Plata y Río Hondo demuestra que su desarrollo no sólo comprende intereses afines al mundo del cine, sino que repercuten de manera directa en los intereses de las localidades donde se realizan. Estos eventos son un espacio de mezcla e intercambio para los diversos agentes

\footnotetext{
${ }^{83}$ Radiofilm, $\mathrm{N}^{\circ}$ 720, 29 abril 1959, p. 47. Además, en la noticia se detallan algunos de los participantes en la comisión: Juan Piazza, presidente; Roberto A. Tálice por el Instituto Nacional de Cinematografía; Ulises Petit de Murat por la Sociedad de Autores; Carlos Alberto Orlando por la Asociación Productora de Películas; Santiago Gómez Cou por la Asociación Argentina de Actores; Augusto César Vatteone por los Directores y Julio C. Viale Paz por la Asociación de Cronistas, entre otros.

${ }^{84}$ Los números de Radiofilm destinados a la difusión del Festival de Cine de Rio Hondo son los $\mathrm{N}^{\circ} 713$, $\mathrm{N}^{\circ}$ $720, \mathrm{~N}^{\circ} 724, \mathrm{~N}^{\circ} 727, \mathrm{~N}^{\circ} 728, \mathrm{~N}^{\circ} 729$ y $\mathrm{N}^{\circ} 730$ entre los meses de marzo y julio de 1959.

${ }^{85}$ Radiofilm, $\mathrm{N}^{\circ} 729,19$ julio 1959, p. 3.

${ }^{86}$ Radiofilm, $\mathrm{N}^{\circ} 729,19$ julio 1959.

${ }^{87}$ Radiofilm, $\mathrm{N}^{\circ} 727,17$ junio 1959.

${ }^{88}$ Radiofilm, $\mathrm{N}^{\circ} 729,19$ julio 1959.
} 
de la industria cinematográfica nacional e internacional, implican la visibilidad de las ciudades, una promoción como atractivo turístico, un crecimiento de la plaza hotelera y gastronómica y demás oportunidades laborales para la región. Pero, además, otorgan a sus habitantes y autoridades la posibilidad de mostrar su cultura e idiosincrasia.

\section{Revistas y clubs para aficionados: sus fines formativos}

En la búsqueda de noticias sobre el cine en las provincias argentinas encontramos regularmente menciones a instituciones y asociaciones, interesadas en el abordaje teórico y técnico de nuestra cinematografía. Sostienen Broitman y Eseverri (2018) que tempranamente diferentes grupos concretaron proyectos culturales alrededor del cine, relacionados con la difusión y la divulgación, caracterizados por la cinefilia, la crítica y la erudición. Estas agrupaciones reciben comúnmente el nombre de cineclubes y desde la década del '30 se extienden en Buenos Aires, pero también en otras regiones del país. En dichos núcleos se reunían investigadores, intelectuales y críticos para intercambiar — con fines formativos-, criterios sobre la nueva forma artística. Los cineclubes fueron de vital importancia para la circulación de películas, ya que muchas veces sus pantallas eran las únicas que proyectaban films de poca rotación en salas y producciones no comerciales. La relevancia de estas sociedades radica en la creación de espacios de pensamiento abiertos a la reflexión, al debate y al análisis de las prácticas cinematográficas. A su vez, en este período existían otro tipo de asociaciones que también se asumen como cineclubes o clubs de aficionados, integrados por realizadores amateurs cuyo objetivo era asistir e informar a sus miembros acerca de la práctica y el quehacer cinematográfico. Este fenómeno tomó impulso, en parte, gracias a la existencia de algunas revistas dedicadas a la práctica de cine. Estas publicaciones se diferenciaron de las destinadas al gran público, por dedicar sus páginas a la difusión de la técnica y al cine no profesional, pero también al surgimiento, funcionamiento y propaganda de las asociaciones de aficionados. La totalidad de estas revistas era editada en la ciudad de Buenos Aires, sin embargo, fue frecuente su envío y distribución en las provincias argentinas, lo que puede observarse a partir de la disposición de un precio diferenciado para la capital y otro para la entrega en el resto del país.

La publicación Cine Club Argentino. Boletín mensual es uno de los ejemplos que hemos encontrado, surgida con el objetivo de comunicar las actividades de la institución que lleva su nombre. Allí se localizan diversos datos de interés para los socios, como las designaciones de funcionarios, las actividades de la comisión directiva y los balances. Pero el cuerpo principal de la revista se constituye de noticias sobre el trabajo de los socios, sus realizaciones, exhibiciones, apuntes formativos sobre la técnica fotográfica y cinematográfica, cursos de perfeccionamiento, concursos e inclusive consultas o inquietudes de los socios. Las autoras Spisanti y Bermúdez (2003), en un análisis sobre la revista, destacan la importancia que esta publicación le daba al cine amateur, ya que indican que lejos de considerarlo un pasatiempo lo aborda como una viva y real inquietud. Además, en las páginas del boletín, el cine es siempre visto como responsable de la formación cultural nacional. En la editorial publicada en su primer número, del año 
Grela Reina y Peterlini. El cine en las provincias argentinas desde las revistas porteñas.

1941, se manifiesta el deseo de ser un espacio abierto para la expresión y el intercambio de ideas entre todos los socios, a la vez que se expresa el interés por extenderse en todo el territorio argentino:

"Llegaremos con este vehículo de propaganda a todos los rincones de la República; cruzaremos fronteras: haremos que el CINE CLUB ARGENTINO sea conocido por todos los aficionados al cine y la fotografía y produciremos excelentes directores, cameramen, argumentistas, iluminadores, escenógrafos, intérpretes, etc." ${ }^{99}$.

La revista se ocupa de mostrar frecuentemente la actividad en las provincias argentinas, compartiendo noticias referentes a los diversos realizadores amateurs que se desplazan por el país en busca de documentar sus paisajes y territorios, como se advierte en una breve nota publicada en la sección Un montón de noticias: "Mendoza y la 'Fiesta de la Vendimia' han servido de tema para varios asociados de nuestro club. Entre ellos, esta Alberto Scarinci, que espera de un momento a otro, la llegada de los rollos de color filmados" ".90. Es habitual encontrar redacciones de este tipo, en las que las regiones nacionales son únicamente tratadas como un mero paisaje captado por la lente de los camarógrafos.

Otro caso es el de la revista Cine técnica. Tratado técnico-práctico de cinematografía, cuya publicación tuvo existencia durante todo el año 1944. El objetivo de la edición, declarado explícitamente en sus primeras páginas, era sistematizar los conocimientos de la técnica cinematográfica en cuatro áreas: dirección, producción, técnica y técnica literaria y artística ${ }^{91}$. Esta idea partió de la editorial Argentina Aristides Quillet S.A. y se editó durante 11 números de aparición mensual. Su contenido presenta claros fines pedagógicos. Allí se puede encontrar información sobre técnicas de dirección, asistencia de dirección, guion y actuación; pero también respecto a la iluminación, sonido, construcción de decorados, utilería y maquillaje para fotografía, entre otras cosas. La publicación puede leerse como una clase o taller a distancia, y representa una herramienta útil para técnicos y aficionados al cine en 8 y $16 \mathrm{~mm}$, público al que estaba dirigida.

Por último, destacamos la existencia de la revista Cine Mínimo. Todo lo referente al cine de 16, 9 y 1/2 y 8 milímetros, que se propone como una guía para acompañar a los principiantes e inexpertos amantes del cine en formato reducido. Se imprimió con una periodicidad irregular a partir de 1948, y si bien hay pocos números conservados en la hemeroteca de la Biblioteca Nacional, la información presente en ellos es muy rica. En sus volúmenes, es posible encontrar referencias tanto a la implementación de nuevas tecnologías, dispositivos y equipamientos como consejos e instrucciones para su

\footnotetext{
${ }^{89}$ Cine Club Argentino. Boletín mensual, N 1 , abril 1941, s/d.

${ }^{90}$ Cine Club Argentino. Boletín mensual, № 11, junio 1942, s/d.

${ }^{91}$ Cine técnica, $\mathrm{N}^{\circ} 1$, enero 1944.
} 
empleo. Así se observa en la respuesta que le otorgó la revista a un abonado cordobés, respecto del funcionamiento de un aparato de proyección:

Jorge Martínez. Cerro de las Rosas, Córdoba. Si en su aparato de proyección se produce centelleo, al pasar películas que en otros proyectores no lo produce, muy bien puede responder a que la potencia luminosa de su proyector es excesiva para el tamaño de la pantalla. Para subsanar este inconveniente tendrá que cambiar la lámpara de proyección por otra de menor potencia o aumentar el tamaño de la pantalla ${ }^{92}$.

La lectura de este apunte permite apreciar que la presencia de las provincias en la prensa especializada no estuvo solamente ligada a la redacción de noticias en las que se señalan acontecimientos cinematográficos regionales, sino también a través de la voz de los suscriptores en las secciones dedicadas a preguntas u opiniones. La interacción con el público, en estos apartados, era cotidiana y la proporción entre lectores porteños y el resto del país equilibrada, lo que expone un claro interés por estos materiales didácticos en toda la república. Esta publicación se interesa en difundir y estimular la producción fílmica de los aficionados. La mayor parte de los materiales realizados son films de corte documental que frecuentemente aprovechan los paisajes regionales como locación o justificación temática, ${ }^{93}$ al igual que observamos en el caso Cine Club Argentino. Boletín mensual.

En Cine Mínimo se observa un anhelo por mostrar el fenómeno del amateurismo como algo creciente y necesario, que acerca la oportunidad de filmar a cualquiera, sin reducir la práctica únicamente al ámbito profesional. De igual manera, se interesa por comunicar la existencia y aparición de diferentes agrupaciones, instituciones y cineclubs a lo largo del país. En 1949, la revista informa la creación de un club de aficionados en Mendoza ${ }^{94}$ y de un nuevo cine club en Córdoba ${ }^{95}$. Sobre estas asociaciones, la revista hace una vigorosa defensa en la editorial de su cuarto número:

El cine club tiene una función capital en el desarrollo de la inquietud del aficionado. Su acción no se circunscribe a colocar al aficionado en condiciones de tomar películas más o menos familiares. Su misión está más allá de llenar necesidades de rutina. El cine club es el que modela la vocación del aficionado orienta su gusto, despierta su inquietud estética. Es una

${ }^{92}$ Cine Mínimo $\mathrm{N}^{\circ} 5$ febrero-marzo 1950, s/d.

${ }^{93}$ Como ejemplo aparece la película Río Atuel. De la nieve a los pámpanos (Marcos Meyer Glikin, 1949), documental sobre la industria vitivinícola en Mendoza, realizado en $16 \mathrm{~mm}$ por un aficionado.

${ }^{94}$ Según la publicación, este club de aficionados se encontraba bajo la dirección de Oscar Guinle. Además, en esa misma noticia, se destaca la existencia de 14 salas de exhibición de películas en $16 \mathrm{~mm}$. en la provincia de Mendoza. (Cine Mínimo. Todo lo referente al cine de 16, 9 y 1/2 y 8 milímetros, $\mathrm{N}^{\circ}$ 3, marzo 1949).

${ }^{95}$ La creación de este cineclub en Córdoba estuvo encabezada por el técnico y publicista José Bullaude y tenía por objetivo organizar un centro para el fomento de las inquietudes por el arte cinematográfico (Cine Mínimo. Todo lo referente al cine de 16, 9 y 1⁄2/2 y 8 milímetros, № 4, septiembre 1949). 
verdadera escuela de cine, del cine arte, campo propicio para el desarrollo de las facultades del aficionado ${ }^{96}$.

La extensa reflexión sobre la vital importancia de los cineclubes es acompañada por un llamado a todos los aficionados del país a agruparse en esas entidades, a fin de difundir y prolongar la cultura cinematográfica Argentina. De modo autodidacta, los aficionados y amantes del cine construyen sus propias herramientas de aprendizaje, se nuclean en asociaciones para reflexionar e intercambiar criterios y para ejercitarse en la práctica. Estos espacios aparecen como una alternativa ante la falta de disponibilidad de estudios académicos formales. Su existencia en toda la extensión del país resultó imprescindible para el establecimiento y la expansión de las prácticas cinematográficas, a la vez que generó alternativas productivas para la realización de películas.

Figura 10. Página editorial de la revista

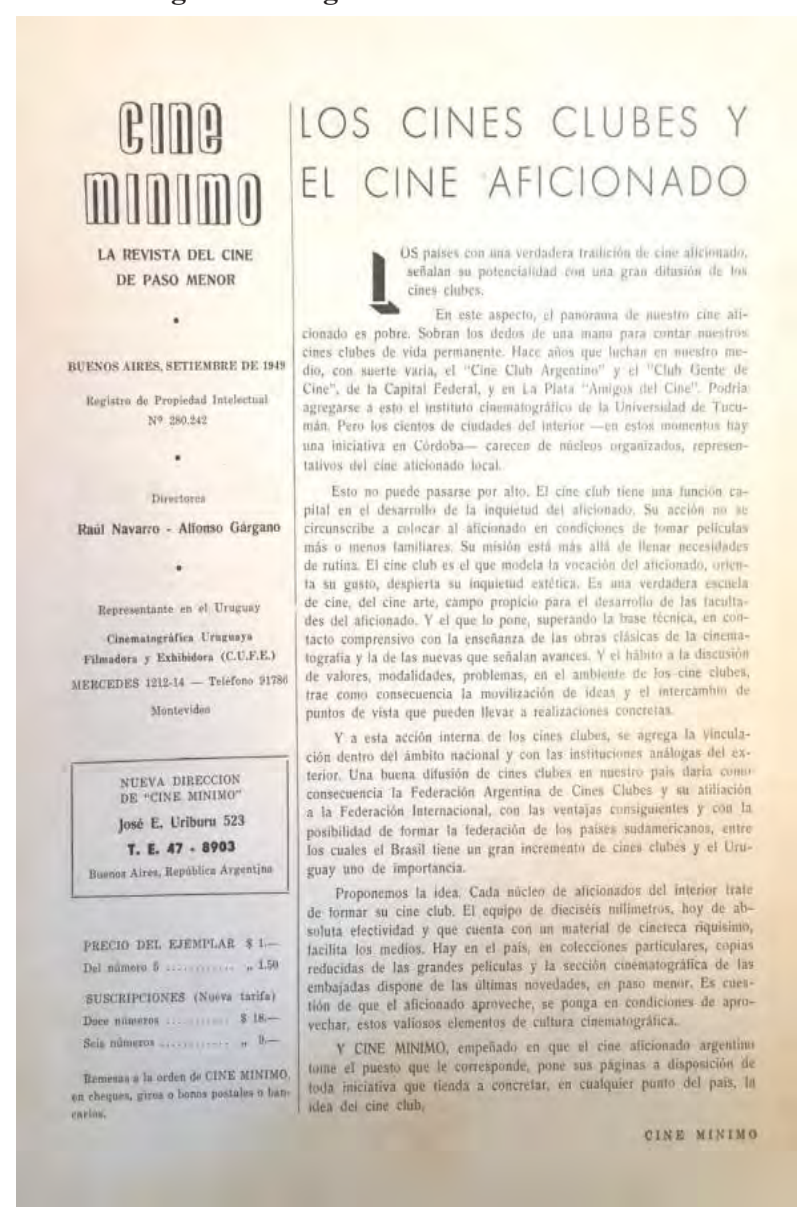

Fuente: Cine Mínimo, № 4, septiembre 1949.

\footnotetext{
${ }^{96}$ Cine Mínimo, $\mathrm{N}^{\circ}$ 4, septiembre, 1949, s/d.
} 


\section{Consideraciones finales}

El relevamiento y estudio realizado de las noticias sobre la actividad cinematográfica en las provincias argentinas, desde las publicaciones especializadas porteñas, nos permite ampliar nuestras investigaciones sobre los cines regionales a la vez que complementa la bibliografía existente. Si bien cada uno de los núcleos de temas tratados aquí necesita evidentemente apoyarse de más búsquedas en distintas fuentes para poder solidificarse, ${ }^{97}$ consideramos que su desarrollo significa un aporte al conocimiento sobre el campo cinematográfico argentino. Aquí planteamos un panorama y un punto de partida, sobre temas relegados muchas veces en la historia y en la historiografía de nuestro cine. Las notas publicadas en las revistas de especialidad colaboran en una reconstrucción de la historia del cine silente en las provincias, al facilitar el conocimiento de aspectos poco difundidos: las producciones panorámicas que se rodaban en las regiones; los desplazamientos de operadores de cámara a zonas turísticas que despiertan especial interés en los espectadores; las posibilidades de distribución de los films mediante la extensión del negocio en distintas aéreas del país; las transiciones y divergencias de opinión en cuanto a las formas de exhibición. A su vez, en el período clásico-industrial de nuestra cinematografía, las noticias se hacen eco de la constitución de productoras provinciales de mayor o menor envergadura, las estrategias de exhibición en las regiones, el surgimiento de asociaciones de aficionados con fines pedagógicos y la celebración de los primeros festivales de cine de la Argentina realizados en ciudades alejadas de Buenos Aires. Más temas podrán aún encontrarse en la lectura atenta de estas publicaciones.

Por otra parte, el análisis de estas revistas especializadas nos permite conocer la perspectiva y mirada del centro (ciudad capital) en torno a todo el país. Cine Universal celebra con entusiasmo las producciones filmadas en el interior y se interesa por las estrellas nacionales. Mientras que La Película, en mayor grado, muestra una mirada más curiosa y preocupada por una expansión y un desarrollo justo del comercio cinematográfico provincial, velando por el interés de sus principales lectores: los distribuidores y exhibidores. Atenta a las fluctuaciones de mercado, señala en sus notas sitios potenciales de crecimiento para la industria cinematográfica, como los referidos al norte argentino y a la ciudad de Rosario, a la vez que expone los actos que considera fraudulentos o de abuso entre las partes comerciales. La revista Radiofilm, en tanto, acompaña ampliamente la actividad cinematográfica argentina y se interesa en difundir los acontecimientos desarrollados en las provincias — producciones, exhibiciones y certámenes de cine-, que son ponderados con admiración y asombro ante los resultados obtenidos. Otras publicaciones como Cosas de cine y Cine Club Argentino. Boletín mensual festejan la conformación de agrupaciones y cineclubes, así como la realización de películas amateurs a lo largo del país.

\footnotetext{
${ }^{97}$ Se sugiere como ejemplo y para las noticias sobre la cinematografía rosarina la lectura de la revista Cinema Star, publicada en Rosario durante la década de 1920. La lectura de un mismo suceso, a través de una revista de cine porteña y de otra de cine santafesino, ofrecerá obviamente una interpretación más acabada.
} 
Grela Reina y Peterlini. El cine en las provincias argentinas desde las revistas porteñas.

Se puede pensar, a priori, que el hecho de ser revistas publicadas en la capital funciona como una limitante en su alcance y comprensión de lo regional. No obstante, un potencial se observa en el involucramiento de las propias revistas en el suceso y en la interacción resultante entre las partes. Nos interesa destacar un ejemplo: en el número 314 de La Película, la redacción se indigna ante una noticia proveniente de Bahía Blanca. Un decreto dictado por el intendente municipal dispone, para las empresas cinematográficas locales, la obligación de presentar previo al comienzo del espectáculo, los certificados que acrediten que las películas a proyectar han sido autorizadas por la Comisión de Censura de Buenos Aires. En caso de exhibirse sin ese requisito, serán sometidas a la comisión local. El semanario considera esta imposición ridícula, emite severas críticas hacia los responsables locales, reclama justicia y demuestra solidaridad hacia los afectados por este hecho: los profesionales del ramo y los espectadores. ${ }^{98}$ Esta nota suelta tendrá mayor repercusión que la esperada y así en el número siguiente se reciben cantidad de cartas de felicitaciones por la postura adoptada y agradecimiento por el apoyo. En reuniones posteriores entre alquiladores y exhibidores de Bahía Blanca se hace mención de la actitud de La Película, toda vez que su nota de defensa a los intereses más puros del cine ha servido de sostén para discutir el problema. ${ }^{99}$

Un estudio que focalice en lo particular de cada revista podría dar luz sobre el rol que ejercieron en la formación de sus lectores de Buenos Aires, en sus interlocutores provinciales y en el negocio cinematográfico en general. La Película, en su recomendación de películas panorámicas, fomenta el conocimiento y gusto del público por éstas, mientras orienta a distribuidores y exhibidores a nuevos mercados y negocios de probable éxito. Al señalar desfavorablemente la persistencia de los biógrafos con café en las provincias, la preocupación no gira exclusivamente en relación a exhibiciones con ruidos molestos y copias gastadas, sino a cómo estos espacios quitaban público a las modernas salas de cine. De ahí el interés en que fuesen eliminados, promoviendo en los espectadores un cambio de hábito. La revista Radiofilm celebra la exhibición de películas como Mansedumbre (Pedro R. Bravo, 1952) realizada y exhibida por primera vez en Tucumán. De ese modo difunde la existencia de producciones regionales más allá de los límites provinciales, enseñándole a los lectores y exhibidores porteños que la presencia de un cine provincial de calidad es posible. Por su parte, las revistas destinadas a los aficionados como Cine Mínimo o Cine Club Argentino abordan la producción de películas realizadas de manera experimental en las regiones argentinas y los desplazamientos de los realizadores a través de las provincias, fomentando así otro modo de producción alternativo y regional.

En su trabajo sobre el aburguesamiento del cine argentino hacia finales de la década de 1930, visto desde las revistas especializadas, Kelly Hopfenblatt (2015, p. 22) sintetiza este rol: "Al mismo tiempo, cada posibilidad que se presentaba como sendero a seguir era exaltada y alabada, buscando la conjunción de los espectadores y la industria

\footnotetext{
${ }_{98}^{98}$ La Película, N314, septiembre 1922.

${ }^{99}$ La Película, $\mathrm{N}^{\circ} 315$, octubre 1922.
} 
sobre estas expectativas". Las revistas porteñas, al mirar a las provincias, no escapan a este anhelo.

\section{Referencias bibliográficas}

Alonso, J. M. (2018). Públicos de cine e investigación aplicada. Un abordaje empírico y cuantitativo de los asistentes al Festival Internacional de Cine de Mar del Plata (MPIFF). Tesis de maestría. Universidad Nacional de Tres de Febrero.

Azcoaga, G. \& Ovejero V. (2014). "Azúcar, peronismo y melodrama en el filme Mansedumbre (1952)", Boletín del Instituto de Historia Argentina y Americana "Dr. Emilio Ravignani. Tercera serie, $\mathrm{N}^{\circ} 41$, segundo semestre. Recuperado de: https://ri.conicet.gov.ar/bitstream/handle/11336/12762/CONICET_Digital_ Nro.15927.pdf? sequence $=1$ \&isAllowed $=\mathrm{y}$

Broitman, A. \& Eseverri M. (2018). "Renovación y actualidad del cineclubismo en la Ciudad de Buenos Aires”, LIS. Letra. Imagen. Sonido. Ciudad mediatizada, Año X, N¹9, Primer semestre. Recuperado de: https://publicaciones.sociales.uba.ar/ index.php/lis/article/view/3884

Campos, M. (2018). "Lo (trans)nacional como eje del circuito de festivales de cine. Una aproximación histórica al diálogo Europa-América Latina", Imagofagia No 17. Recuperado de: http://www.asaeca.org/imagofagia/index.php/imagofagia/article/ view/1441/1315

Ciancio, M. B. (2013). "Estudios sobre cine en Argentina. Consideraciones epistemológicas y metodológicas”, Nuevo Mundo Mundos Nuevos. Recuperado de: https://journals.openedition.org/nuevomundo/66138

Cuarterolo, A. (2009). "Primeros debates y reflexiones en torno al cine nacional". En A. L. Lusnich y P. Piedras (editores), Una historia del cine político y social en Argentina. Formas, estilos y registros (1896-1969), Volumen I. Buenos Aires: Nueva Librería.

Di Núbila, D. (1959). Historia del Cine Argentino. Buenos Aires: Cruz de Malta.

España, C. (comp.) (2000). Cine argentino. Industria y clasicismo (1933-1955) Vol. I y II. Buenos Aires: Fondo Nacional de las Artes.

Eujanian, A. (1999). Historia de revistas argentinas 1900-1950. La conquista del público. Buenos Aires: Asociación Argentina de Editores de Revistas.

Flores, S. (2019). "La producción regional en el cine argentino y latinoamericano", Imagofagia, $\mathrm{N}^{\circ}$ 20. Recuperado de: http://www.asaeca.org/imagofagia/index. php/imagofagia/article/view/1935

Gámir Orueta, A. \& Valdés C. M. (2007). Cine y geografía: espacio geográfico, paisaje y territorio en las producciones cinematográficas, Boletín de la A.G.E., $\mathrm{N}^{\circ}$ 45. Recuperado de: file://C:/Users/coska/AppData/Local/Temp/DialnetCineYGeografia-2519817_1.pdf

Kelly Hopfenblatt, A. (2015). Un cine en transición: el aburguesamiento del cine argentino visto a través de las revistas especializadas, Imagofagia. $\mathrm{N}^{0} 12$. Recuperado de: http://www.asaeca.org/imagofagia/index.php/imagofagia/article/ view/827 
Kriger, C. (directora) (2003). Páginas de cine. Buenos Aires: Museo del Cine / Archivo General de la Nación.

Kriger, C. (2004). "Inolvidables jornadas vivió Mar del Plata: Perón junto a las estrellas", Archivos de la filmoteca: Revista de estudios históricos sobre la imagen, $\mathrm{N}^{\mathrm{0}} 46$.

Kriger, C. (2014). "Estudios sobre cine clásico en Argentina: de la perspectiva nacional a la comparada”, AdVersus, XI. Recuperado de: http://www.adversus.org/indice/ nro-26/dossier/XI2609.pdf

Levinson, A. (2011). Cine en el país del viento. Antártida y Patagonia en el cine argentino de los primeros tiempos. Río Negro: Fondo Editorial Rionegrino.

Mafud, L. (2016). La imagen ausente. Buenos Aires: Teseo / Ediciones Biblioteca Nacional.

Morales, I. (2017). "La revista Cinegraf (1932-1937): crítica especializada, modernidad conservadora y la búsqueda de una imagen nacional", Perspectivas de la Comunicación, Vol. 10, N 2. Recuperado de: http://revistas.ufro.cl/ojs/index. $\mathrm{php} / \mathrm{perspectivas/article/view/735}$

Ozollo, J. (2004). "La California Argentina. Film Andes y la industria vitivinícola mendocina(1944-1957)", Revista Universum, No 19, Vol.2. Recuperadode: https:// scielo.conicyt.cl/scielo.php?script=sci_arttext\&pid=S0718-23762004000200008

Pardo, S. (2016). "Los estudios sobre el cine argentino del período clásico industrial: un panorama histórico", Questión, Vol. 1, N. ${ }^{\circ} 49$. Recuperado de: https://perio.unlp. edu.ar/ojs/index.php/question/article/view/3107

Pita González, A. \& Grillo M. C. (2015). "Una propuesta de análisis para el estudio de revistas culturales", Revista Latinoamericana de Metodología de las Ciencias Sociales (Relmecs),Vol. $5 \mathrm{~N}^{\mathrm{o}}$ 1. Recuperado de: http://www.memoria.fahce.unlp. edu.ar/art_revistas/p.r.6669/pr.6669.pdf

Quiroga, H. (2007). Literatura y cine. Buenos Aires: Losada

Rosas Mantecón, A. (2017). "Conflictos en la sala: el cine era mudo pero no silencioso". En Ir al cine. Antropología de los públicos, la ciudad y las pantallas. CDMX: Gedisa Editorial / UAM Iztapalapa

Spisanti, R. \& Bermúdez J. (2003). "Boletín mensual de cine”. En Kriger, Clara (directora), Páginas de cine. Buenos Aires: Museo del Cine / Archivo General de la Nación.

Torres Ríos, L. (1922). "Cinematografía Nacional. Historia ligera”. Crítica, número extraordinario.

Triana Toribio, N. (2007). "El festival de los cinéfilos transnacionales: el festival cinematográfico internacional de la República Argentina en Mar del Plata, 19591970", Secuencias. Revista de historia del cine, $N^{\circ} 25$. Recuperado de: https:// revistas.uam.es/secuencias/article/view/4080/4349

\section{Fuentes}

Boletín de la Academia de Artes y Ciencias Cinematográficas de la Argentina.

Cine Club Argentino. Boletín mensual.

Cine Mínimo. Todo lo referente al cine de 16, 9 y 1/2 y 8 milímetros. 
Cine Técnica. Tratado técnico-práctico de cinematografía.

Cine Universal.

Cinegraf.

Cinema Chat.

Cosas de cine.

Imparcial Film.

La Película. Semanario cinematográfico sudamericano.

Magazine Cinematográfico.

Maravillas Films.

Primer Plano.

Radiofilm.

Set.

Sideral. 